Portland State University

PDXScholar

\title{
An Examination of Factors Influencing Self Versus Supervisory Referrals to an Employee Assistance Program
}

Jeffrey M. Gray

Portland State University

Follow this and additional works at: https://pdxscholar.library.pdx.edu/open_access_etds

Part of the Psychology Commons

Let us know how access to this document benefits you.

\section{Recommended Citation}

Gray, Jeffrey M., "An Examination of Factors Influencing Self Versus Supervisory Referrals to an Employee Assistance Program" (1996). Dissertations and Theses. Paper 5192.

https://doi.org/10.15760/etd.7068

This Thesis is brought to you for free and open access. It has been accepted for inclusion in Dissertations and Theses by an authorized administrator of PDXScholar. Please contact us if we can make this document more accessible: pdxscholar@pdx.edu. 


\section{THESIS APPROVAL}

The abstract and thesis of Jeffrey M. Gray for the Master of Science in Psychology were presented February 12, 1996 and accepted by the thesis committee and the department.

COMMITTEE APPROVALS:
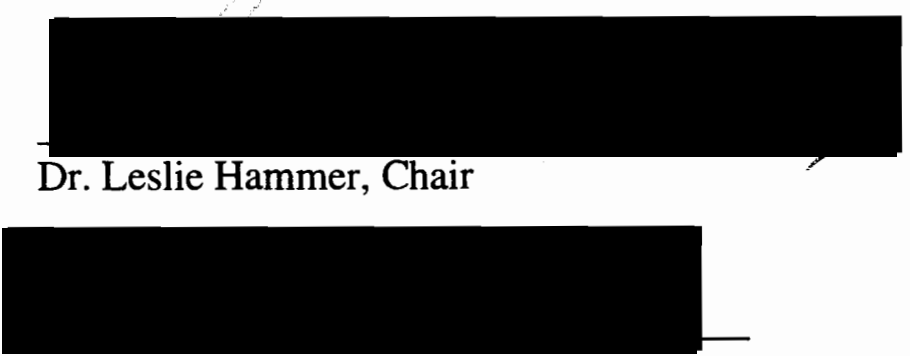

Dr. Dean Frost

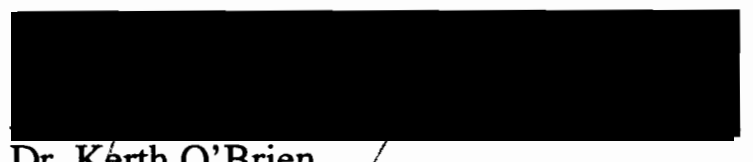

Dr. Kerth O'Brien

DEPARTMENT APPROVAL:

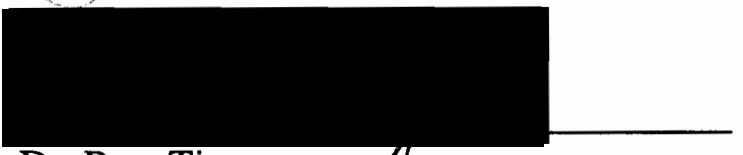

Dr. Pam Tierney

Representative of thd Office of Graduate Studies

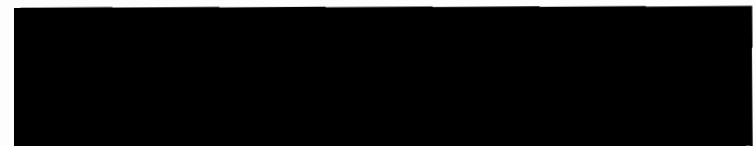

Dr. James Paulson

Department of Psychology

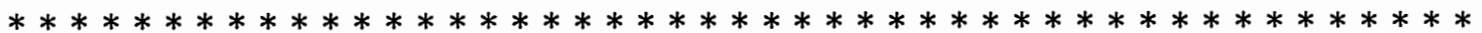

ACCEPTED FOR PORTLAND STATE UNIVERSITY BY THE LIBRARY

by

on $\$ 2$

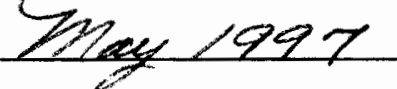


An abstract of the thesis of Jeffrey M. Gray for the Master of Science in Psychology presented February 12, 1996.

Title: An Examination of Factors Influencing Self Versus Supervisory Referrals to an Employee Assistance Program.

It is estimated that $20 \%$ of American employees have some sort of a personal problem that substantially hinders their work performance. This can result in future consequences for both the employee and employer, such as loss of job by the employee and increased expenses for the employer. Employee Assistance Programs (EAP's) are one of the leading approaches used in an attempt to mitigate problems experienced by distressed workers. EAP's are formal intervention systems that assist employees with a variety of personal problems. Studies have shown that EAP's are effective in treating employee problems, however, most employees do not take advantage of this service The goal of this study was to identify factors that predict increased likelihood of employee self referrals to an EAP and whether there were any significant differences in factors relating to self versus supervisory referrals to an EAP. Previous literature had not explored the latter issue.

Seventy-one subjects, 37 males and 34 females, from a government agency participated in the study. Of the 71 participants, 33 were supervisors and 38 were subordinate employees. Each subject completed a Likert-type survey that assessed their willingness to either self refer themselves or refer their subordinate employees to an EAP for a variety of problems. Supervisors assessed their willingness to refer subordinate employees to an EAP, while subordinates assessed their willingness to self refer to an EAP . 
Multiple regression analyses indicated that the variables of familiarity, embarrassment, attention, effectiveness, trust, control and referral by supervisor were significant in predicting an employees' willingness to self refer to an EAP for a variety of personal problems. Furthermore, analyses suggested that there was a difference between employees and supervisors in factors related to willingness to refer to an EAP. The primary difference was that supervisors mainly considered the overall effectiveness of the EAP program when deciding willingness to refer employees while employees mostly considered job security concerns, such as referral by supervisor or trust in confidentiality, when deciding willingness to self refer to an EAP. Future research should investigate this issue further to examine if this conclusion can be generalized to other organizations. 


\section{AN EXAMINATION OF FACTORS INFLUENCING \\ SELF VERSUS SUPERVISORY REFERRALS TO AN \\ EMPLOYEE ASSISTANCE PROGRAM}

by

JEFFREY M. GRAY

A thesis submitted in partial fulfillment of the requirements for the degree of

\section{MASTER OF SCIENCE \\ in \\ PSYCHOLOGY}

Portland State University

1996 
An Examination Of Factors Influencing Self Versus Supervisory

Referrals To An Employee Assistance Program

It is estimated that $20 \%$ of American employees should be classified as being "distressed" workers (Johnson, 1985). According to Johnson, being "distressed" denotes that an individual's personal problems create an impediment to successful job performance. For example, a worker may be classified as being distressed if he/she has a chemical dependency problem that interferes with his/her job performance. This can lead to several consequences for the company as well as for the employee. First of all, for the employer there may be several costs involved when dealing with an employee who has a chemical dependency problem (Dixon, 1988). Some consequences and expenses that may transpire as a result of this problem are higher absenteeism, higher medical costs, lower productivity, and the cost to replace the worker if the worker is terminated (Smith \& Mahoney, 1989). Additional implications for the employee include having to deal with such problems as possible loss of job, time and cost for rehabilitation, and family distress.

Employee Assistance Programs (EAP's) are one of the leading approaches in an attempt to alleviate problems experienced by "distressed" workers (Webb, 1991). EAP's have evolved over the past five decades from an initial focus on alcohol abuse to currently providing a wide range of services to a wide variety of problems (Soto, 1991). They are formal intervention systems that identify and assist organizational members with a variety of personal problems that may be affecting their job performance (Milne, Blum \& Roman, 1994). EAP's are conducted either in support groups comprised of workers with similar problems (Wegener, 1992) or administered on an individual basis by counselors (Fizek \& Zare, 1988). In addition, EAP's can be 
used as a resource for supervisors to encounter problem employees and propose they seek help (i.e., supervisory referrals) or as a resource for employees to pursue by themselves for work-related problems that they perceive themselves or their family members having (i.e., self referral) (Milne et al., 1994).

Employee assistance programs are becoming increasingly more accessible in the workplace. Luthans and Waldersee (1990) noted that recent estimates suggested there are over 10,000 EAP's in place and about three-fourths of America's 500 largest firms have EAP's available to their employees. However, it is estimated that only $7 \%$ of employees who have access to an EAP actually utilize the EAP (Hall, Vacc \& Kissling, 1991). If only $7 \%$ of employees use EAP's, and it is estimated that at least $20 \%$ of employees are in need of some form of counseling (Johnson, 1985), then there need to be investigations to ascertain why there is such a disparity between those who get help through an EAP and those who could benefit from an EAP. It is important to discover the factors that increase the use and positive perceptions of EAP effectiveness. In 1983, Gam, Sauser, Evan and Lair stated that "data related to the effectiveness of EAP's are virtually non-existent in the professional literature" (p. 63). Since that time, there have been varying attempts to find out what definitive elements may facilitate one to use an EAP.

The goal of this study was to identify factors that predict increased likelihood of employee self referrals to an EAP. In addition, the study examined whether there were any significant differences in factors related to self versus supervisory referrals.

Previous literature has not explored this issue. A review of the research relevant to this topic will first be described, which then will be followed by a description of the study. 


\section{EAP Effectiveness}

A study of EAP effectiveness was conducted by the McDonnell Douglas Corporation (Smith \& Mahoney, 1989). A total of more than 20,000 employees of McDonnell Douglas served as subjects in three groups. The reported findings did not indicate the exact number of employees for each group. The first group of subjects were all employees who utilized the EAP from 1985 to 1989 either by self or supervisory referral. A second group of subjects consisted of employees who were treated for alcoholism, chemical dependency, or mental illness during the same period but who had chosen not to use the EAP services. The latter group of subjects were referred to as the "Non-EAP" group. Finally, a control group was comprised of employees who were not treated at any time for substance abuse or mental illness. Absenteeism and medical claims were used as objective measures for this study.

Results indicated that the EAP at McDonnell Douglas was effective in reducing absenteeism and medical claims. For example, EAP clients treated for chemical dependencies lost $44 \%$ fewer days than those employees treated for chemical dependency outside of the EAP. Another example that illustrated the effectiveness of the EAP was that the total four year costs for EAP treatment of chemical dependency was $\$ 7,370$ lower than Non-EAP treatment of chemical dependency. Results were similar for the treatment of mental illness.

The reduction in absenteeism and medical claims for those employees who utilized the EAP helped to reduce the financial burden of McDonnell Douglas. The offset value of EAP services of those who utilized the services was an estimated amount of $\$ 5.1$ million, with $\$ 4.3$ million being saved from all medical claims and $\$ 0.8$ million being saved from absenteeism. 
The increase in worker stability and decrease in financial burden of the company illustrated the effectiveness of the McDonnell Douglas EAP. The McDonnell Douglas study clearly showed that the EAP was capable of helping the company while attempting to assist employees with their problems.

\section{Previous Research On Willingness To Self Refer To EAP}

A large study conducted by Macdonald and Dooley (1990) reviewed 91 different EAP's, instituted between 1973 and 1987, to examine factors associated with increase usage of an EAP and perceived effectiveness of an EAP. The general conclusions of the study were that effective EAP's were found to promote voluntary referrals, contain more procedures to protect against confidentiality problems, and mention the importance of informing employees about the availability of an EAP. A beneficial contribution of the study was that the authors illustrated the organizational components that are needed to increase EAP usage. However, the study did not examine specific personal characteristics of employees who are most likely to use the EAP.

One study that explored the employee attitudes that were related to their willingness to use EAP's for alcohol abuse problems was conducted by Harris and Fennell (1988). One hundred and fifty employees, 85 males and 65 females, from a midwestern financial institution served as subjects in the study. Each employee attended a 90 minute interview session where they answered various questions concerning their willingness to use an EAP. The questions covered such areas as familiarity with the EAP program, trust in the confidentiality of the program, the control that the company might impose over the employee who uses the EAP service, embarrassment for attending the EAP, effectiveness of the EAP in treating alcoholism, 
and the willingness of the employee to use the EAP. Each question was answered using a 1 to 10 scale ranging from "not at all" to "very much". An example of a question asked was, "From 1 to 10 , how much do you think the program will try to control you?" Regression analyses were used to predict employees' willingness to use EAP services. Results from the study indicated that trust in the confidentiality of the $\operatorname{EAP}(b=.38, p<.01)$, familiarity with the $\operatorname{EAP}(b=.21, p<.01)$ and personal attention from the EAP $(b=.44, p<.01)$ were significant predictors of respondents' willingness to participate in an EAP.

In addition, Harris and Fennell (1988) examined gender differences in willingness to attend an EAP. No significant associations were found between employee gender and willingness to attend an EAP. The authors concluded that this may have resulted because, "although women may be more likely than men to identify themselves of having a problem, perhaps men and women are equally likely to seek help once they have recognized the problem." (p.435)

The Harris and Fennell (1988) study went beyond others by investigating attitudinal factors related to employees' willingness to use an EAP. The general conclusions of the study were that trust, familiarity, and personal attention from the EAP staff would increase employees' willingness to make use of the EAP for an alcohol abuse problem. However, since the study only examined willingness to attend an EAP for alcohol abuse, the findings cannot be generalized to other purposes to attend an EAP, such as family problems. It has been mentioned in other reviews of the literature (Scanlon, 1986) that there might be a difference in employees' willingness to use an EAP depending upon the personal problem of the employee. Compared to other personal problems such as marital or financial issues, Scanlon felt employees are less 
Referral 6

likely to use an EAP to deal with an alcohol problem. The basis for his reasoning was that people are less likely to openly admit to alcohol abuse in fear of being socially embarrassed. The Harris and Fennell study can be improved by examining other personal problems, along with alcohol abuse, in determining factors that influence employees' willingness to self refer to an employee assistance program. A more complex study examining personal variables used to determine willingness to self refer to an EAP was conducted by Hall, Vacc and Kissling (1991). Hall et al. surveyed 62 employees, 38 females and 24 males, at a large telephone communications company. Specifically, they examined the following predictors of EAP usage: 1) sociodemographical, 2) social psychological, 3) sociocultural, 4) organizational and 5) community. Figure 1 shows the relationships between the five predictor categories and represents the model that the study attempted to test. As figure 1 shows, both sociodemographical and sociocultural indicators affect social psychological indicators which in turn influences one's propensity to use an EAP. Social psychological indicators also influence the organizational variables. In addition, Hall et al. predicted that community and organizational factors will influence one's propensity to make use of an employee assistance program.

See Figure 1 on page 6 a

Hall et al. (1991) used a questionnaire developed by Hall (1990) to assess the relationship between the five categories and the likelihood of employees' use of EAP services for various types of problems, such as alcohol, career, family, psychological, emotional, legal, and financial problems. Stepwise hierarchical multiple regression 
Figure 1

Model For Examining EAP Utilization from Hall et al.

\section{Sociodemographic}
Age
Race
Sex
Job category
Income
Education

\section{Sociocultural}

One's social support network

\section{Organizational}

Employee perception of supervisor's attitudes towards EAP Convenience of EAP Confidentiality of EAP

Use of EAP to Keep Job

Propensity to use EAP

Social Psychological

Problem recognition

Problem severity

Community

Previous Use

Knowledge of other services

Cost of other services Convenience of other services 
analyses were conducted to determine factors related to willingness to self refer to an EAP. Table 1 summarizes the significant results of the Hall et al. study.

See Table 1 on page 7A

Of the five areas studied, organizational variables were the sole determinants of likelihood to use EAP services. The variables of confidentiality, knowledge of EAP, use of EAP to keep job, convenience of EAP, and supervisor's attitude toward the EAP that were shown to be significant predictors of willingness to use EAP services in Table 1 all fall under the organizational category from figure 1. As a result, the Hall et al. (1991) model was not shown to be completely accurate in predicting employee willingness to use an EAP. Only the organizational category was shown to have a meaningful influence on one's propensity to use EAP services. The authors of the study concluded, "the evidence in this current study is not conclusive" (p.73), indicating a need for further research. Hall et al. explained one possible reason for this was that, "it may have resulted from model overfitting, using too many predictor variables for the number of participants available" (p. 72), also suggesting that perhaps a simpler survey will achieve better results.

A major shortcoming of this study was that it should have examined whether there were any differences in employee willingness to use the EAP due to the type of personal problem. For example, what factors will affect willingness to self refer for different problems? The study asked questions pertaining to different personal problems but did not investigate whether there were any significant associations 
Table 1

Significant predictors of EAP usage from Hall et al. (1991)

\begin{tabular}{llcc} 
Type of problem & Significant variable & $\underline{\beta}$ & $\underline{p}$ \\
& & & \\
\hline Alcohol & Confidentiality & 1.071 & $<.01$ \\
Alcohol & Knowledge & 2.706 & $<.01$ \\
Career & Convenience & 0.886 & $<.01$ \\
Drug & Confidentiality & 0.897 & $<.01$ \\
Drug & Supervisor's attitude & 1.165 & $<.01$ \\
Drug & Knowledge & 2.764 & $<.01$ \\
Psychological & Confidentiality & 0.632 & $<.01$ \\
Family & Knowledge & 2.157 & $<.01$ \\
Financial & Use of EAP to keep job & -0.586 & $<.01$ \\
Supervisor referral & Use of EAP to keep job & -0.197 & $<.07$ \\
Supervisor referral & Supervisor's attitude & 0.303 & $<.01$
\end{tabular}


between the type of personal problem with one's willingness to self refer to an EAP. This notion was examined in the present study.

It is important to note that part of the findings from the Hall et al. (1991) study overlapped with the findings from the Harris et al. (1988) study. The earlier study concluded that familiarity and trust were significant predictors of an employees' willingness to make use of EAP services for alcohol abuse. In addition, the later study reached a conclusion that confidentiality and knowledge of the EAP were significant predictors of EAP usage for several personal problems, such as alcohol, drug, and psychological. The constructs of trust in an EAP and the perceived confidentiality of an EAP can be thought of as similar. In addition, knowledge of an EAP and familiarity of an EAP are related in meaning. In sum, the Hall et al. study confirmed the findings from the Harris et al. study while also extending the conclusions to other personal problems.

\section{Alternative Referral Sources}

Along with employee self referral to an EAP, there are two additional referral types that are used frequently in the work place. First, referrals by co-workers of employees to an EAP account for approximately $10 \%$ of all EAP referrals (Brodzinski \& Goyer, 1987). More importantly, Brodzinski et al. (1987) reported supervisory referrals of employees to an EAP account for approximately $33 \%$ of all referrals. However, although approximately one-third of all EAP referrals are done by supervisors, research has been relatively non-existent in examining the factors that differentiate supervisory versus self referrals.

A study that examined the effects of staff status on the number of EAP referrals was conducted by Gerstein, Gaber, Dainas, and Duffy (1993). The study examined if 
the rate of referral of workers to an EAP was different between supervisors and employee co-workers. The authors predicted that supervisors would suggest more EAP referrals than co-workers. Their reasoning for this was that supervisors would have more knowledge of the EAP service and that they could use their higher status power to refer distressed workers to an EAP compared to a lower level employee. A total of 389 participants, comprised of 137 supervisors and 252 employees, completed a questionnaire pertaining to their likelihood to refer others to an EAP. An ANOVA indicated that there was an effect for staff status $(\mathrm{F}(1,388)=45.6, \underline{p}<.01)$, showing that supervisors suggested significantly more EAP referrals than did co-workers. The findings showed that 92 of the 137 supervisors referred employees to an EAP in the past. Only 18 of the 252 employees surveyed reported having referred a coworker to an EAP. The authors concluded that the results suggested that the supervisors were more capable of identifying impaired workers than were lower level employees due to their higher awareness of the EAP, their responsibility of being a supervisor, and their higher rates of referrals. The findings from this study were interesting, but it left out an important issue; Are there differences between supervisory and self referrals? It would be useful in order to better understand factors influencing EAP usage to conduct research that examines if there are any differences between self and supervisory referral rates and, more importantly, to examine if there are differences between the two in factors related to EAP usage. If there is a difference, separate strategies might have to be used for increasing self and supervisory referrals to an EAP. Research pertaining to this issue has been non-existent. As a result, this study examined whether there were differences between supervisors and employees in factors related to willingness to refer to an EAP. 
The Study

The study examined four separate areas of EAP usage. First, the study examined general factors influencing employee self referrals to an EAP. Second, the study investigated differences between supervisors and employees in factors related to willingness to refer to an EAP. As a result of literature being non-existent in this subject matter, this became the primary focus of the study. In addition, the study also looked at gender differences in willingness to refer to an EAP. Finally, exploratory research was conducted to examine differences in those who have used an EAP in the past and those who have not in terms of willingness to refer.

\section{Factors Influencing Employee Self Referral To An EAP}

This section of the study combined aspects of both the Harris and Fennell (1988) and the Hall et al. (1991) studies. The first goal of the study was to discover which variables would lead an employee to refer oneself to an EAP when confronted with a variety of potential problems. The study used the seven predictor variables, also called employee attitudes towards the EAP, from the Harris et al. study. The Harris et al. study examined the relationships of familiarity, embarrassment, personal attention from EAP, effectiveness, trust, control the EAP might impose over the employee, and referral by supervisor with one's willingness to self refer to the EAP for an alcohol abuse problem. All seven employee attitudes towards the EAP are more clearly defined in Table 2 and were tested separately with various problems that an employee might have that can be possibly resolved through the use of an EAP service. The various reasons that one may have to participate in an EAP, that were examined in this study, were self-referral for alcohol, drug, psychological, career, financial, and family problems. 
Referral 11

See Table 2 on page $11 \mathrm{~A}$

Specific results from the Harris et al. (1988) study concluded that trust and familiarity were significant predictors of an employee's self referral to an EAP for an alcohol abuse problem. In addition to confirming the results from the Harris et al. study, Hall et al. (1991) found trust to be a significant predictor of self referral for drug abuse and psychological problems and found familiarity to be a significant predictor of self referral for drug abuse and family problems. These results led to Hypothesis 1 . The terms below are defined in Table 2 .

Hypothesis 1a: This study will confirm the Harris et al. results that embarrassment, trust, attention, control, familiarity, effectiveness and referral by supervisor will be significant predictors of willingness to self refer for an alcohol abuse problem.

Hypothesis $1 \mathrm{~b}$ : The predictor variables of embarrassment, trust, attention, control, familiarity, effectiveness and referral by supervisor will be significant predictors of willingness to self refer for a drug abuse problem. Hypothesis 1c: The predictor variables of embarrassment, trust, attention, control, familiarity, effectiveness and referral by supervisor will be significant predictors of willingness to self refer for a psychological problem.

Hypothesis 1d: The predictor variables of embarrassment, trust, attention, control, familiarity, effectiveness and referral by supervisor will be significant predictors of willingness to self refer for a financial problem. 
Table 2

Employee attitudes towards the EAP

Attitude Definition Sample Question

Familiarity How familiar employee is with

what is done with the EAP.

Embarrassment How embarrassed employee

would be if others knew he/she went to the EAP.

Attention

How much personal attention one would have from EAP.

Effectiveness How effective is EAP for treating employees' problems.

Trust

Control

Supervisor referral
How much employee feels EAP

can be trusted to keep

information confidential.

How much would the EAP try

to influence the way one acts or

thinks.

Would employee attend an EAP if they were referred to go by their immediate supervisor.
"I am familiar with the EAP provided by my work in treating alcohol abuse" "I would feel embarrassed if I attended the EAP provided by my for a drug abuse problem"

"I would feel the EAP would give me the appropriate attention that I would need to treat my career problems" "I perceive the EAP as being effective in assisting me with financial problems" "I would have trust in the EAP to keep any information confidential about me if I attended it for family problems" "I would feel that the EAP would NOT try to take control of my daily routine if I attended it for psychological problems" "If my supervisor recommended that I attend the EAP because he/she felt I was experiencing family troubles, I would attend" 
Hypothesis 1e: The predictor variables of embarrassment, trust, attention, control, familiarity, effectiveness and referral by supervisor will be significant predictors of willingness to self refer for a career problem. Hypothesis 1f: The predictor variables of embarrassment, trust, attention, control, familiarity, effectiveness and referral by supervisor will be significant predictors of willingness to self refer for a family problem. As mentioned previously, Scanlon (1986) suggested that people may vary in their use of an EAP depending on the problem. For example, employees may be less likely to admit to an alcohol abuse problem and, consequently, be less willing to attend an EAP. As a result of this, the notion from the Hall et al. (1991) study to question the employee over a variety of problems was integrated with the predictor variables from the Harris and Fennell (1988) study. However, this study went beyond the Hall et al. study by additionally testing for any significant differences between the various problems. It was also expected that the more severe and potentially embarrassing the problem was to the employee (such as alcohol, drug, and psychological problems), the less likely the employee would be willing to use an EAP (as compared to career, financial, and family problems).

Hypothesis 2: Employees will be more willing to refer oneself to an EAP for career, financial, and family problems than for drug, alcohol, and psychological problems.

\section{Examination Of Self Versus Supervisory Referrals To An EAP}

The study also examined if there were any differences between supervisory and self predictors of willingness to refer to an EAP. Specifically, would a supervisor be more willing to refer a subordinate to an EAP than that subordinate would be willing to 
self refer himself or herself, and, are there differences in the factors that determine self and supervisory referrals? No prior research has previously examined this topic. However, Gerstein et al. (1993) illustrated a difference in referral rates of supervisors and employees dealing with other workers. Supervisors suggested more referrals of subordinates than did co-workers. The authors felt this should be true because supervisors have more knowledge of an EAP than do subordinates and that they are more capable of identifying impaired workers. With this information and the literature from Scanlon (1986) that suggests employees might not be willing to admit openly to a potentially embarrassing problem, Hypothesis 3 was formulated.

Hypothesis 3: There will be a significant difference between supervisory and self willingness to refer such that supervisors will be more willing to refer across all six problems.

Further analysis will be conducted to determine if there are any differences in factors related to self versus supervisory referrals. For example, are different predictor variables significant for supervisory referrals as compared to self referrals?

\section{Examination Of Gender Differences In EAP Usage}

In addition, the study investigated gender differences in employees' willingness to self refer. The Harris and Fennell (1988) study also examined this issue. The study found no significant gender differences. However, Trice and Breyer (1979) suggested that men and women may react differently to the use of EAP's. They theorized that women would be more willing than men to seek treatment for a problem. Trice and Breyer relied upon traditional sex-role theory for their reasoning, which was that the more nurturing, supportive roles considered appropriate for women might also make then more willing to accept EAP's in an attempt to resolve their problems. 
Furthermore, separate studies by Leaf (1987) and Good (1989) found that men were less likely to seek professional help than women. Both studies summarized that men (as compared to women) try to solve their own problems without the assistance of professional help and they perceive pride as a motivational force for men not being so willing to seek help. The current study attempted to examine whether there were any gender differences in self referral. It was expected that the reasoning from Trice and Breyer, Leaf and Good would prevail.

Hypothesis 4 : Women will be significantly more willing than men to refer themselves to an EAP to deal with each of the six problems under study.

\section{Exploratory Questions}

Finally, the study conducted exploratory research to examine any differences in predicting employee willingness to use an EAP between those who have previously made use of the EAP service and those who have never used the EAP service. The previously mentioned literature did not examine this topic. It was of interest to examine if prior use of the EAP would affect anticipated future use. This inquiry will be useful in recommending changes in future EAP makeup. For example, if employees who have previously used the EAP report less willingness to use the EAP in the future than those who have never used the EAP, this would show that perhaps the EAP needs to be restructured to encourage future use by its clients. 
Method

\section{$\underline{\text { Subjects }}$}

Six hundred employees from a government agency that offers an employee assistance program to its employees in the Portland area were asked to serve as subjects. Most of the employees surveyed were blue collar workers. A total of 71 subjects, 37 males and 34 females, participated in the study. Of the 71 participants, 33 were supervisors and 38 were subordinate employees. Finally, 31 out of the 71 subjects that completed a survey had previous experience with the EAP at their company.

\section{Materials}

The subjects who participated filled out a questionnaire on their own time to determine their likelihood to use an EAP. The questionnaire was broken down into two parts. Supervisors and subordinates filled out similar surveys except that supervisors answered questions pertaining to themselves referring subordinate employees to an EAP whereas subordinates answered questions relating to their likelihood to self refer themselves to an EAP. Copies of the surveys are presented in Appendices A and B.

The first section of the questionnaire constituted the majority of the survey. This section combined elements of both the Harris and Fennell (1988) study and the Hall et al.(1991) study. More specifically, the first section of the questionnaire was a Likert-type scale from 1 to 6 , ranging from "strongly disagree" to "strongly agree". This section of the survey was different for subordinates and supervisors. First, for the subordinates, they were surveyed about their familiarity with the EAP, perceived embarrassment by attending the EAP, perceived attention from the EAP, amount of 
Referral 16

control the EAP may impose over the employee, perceived confidentiality of the EAP, perceived effectiveness of the EAP to treat the problem, willingness to attend if recommended by supervisor, and willingness to self refer oneself to the EAP. All eight of the above variables were used with six different possible problems that employees may encounter, which were: 1) Alcohol abuse problems such as daily excessive drinking, 2) Drug abuse problems such as frequent marijuana usage, 3) Career problems such as lack of job satisfaction or trouble with a coworker, 4) Financial difficulties such as ways to budget one's money, 5) Family troubles such as marital problems, and 6) Psychological problems such as depression. See Appendix A for the subordinate employee survey. For all six possible problems, the question that pertained to willingness to self refer was the dependent variable and the remaining seven questions were the independent variables.

The survey designed for the supervisors was similar to the one previously mentioned. The difference was that the questions did not pertain to themselves, but pertained to their subordinates. The questions were probing the likelihood of supervisors' willingness to refer subordinate employees to the EAP. See Appendix B for a copy of the supervisor survey.

The second section of the questionnaire was identical for both the supervisors and the subordinates. This section included questions on age, gender, marital status, parental status, education, job tenure, and previous EAP usage.

\section{Procedure}

The questionnaires were distributed to all supervisors and subordinates separately by the Director of Occupational Health and Safety on company premises during company time. The subjects were allowed to complete the survey that applied 
to them outside of work. The questionnaires included a self addressed stamped envelope in order for the employee to return the survey

Results

\section{Descriptive Statistics}

Response rate for this study was $11.83 \%$. A total of 71 subjects, out of a possible 600 employees, participated. The participants ranged from 24 to 53 years old with a mean age of 39.21 years and a standard deviation of 8.19 . The average tenure of the subjects was 10 years. Of the 71 participants, 38 were subordinate employees and 33 were supervisors. In addition, 31 subjects reported having previously used the EAP at their company. Finally, 34 females (16 supervisors and 18 subordinates) and 37 males (17 supervisors and 20 subordinates) were involved in the study.

Table 3 outlines the mean scores for the dependent variables of employees' and supervisors' willingness to refer to the EAP for each of the six problems that were discussed in the survey. Likewise, Tables 4 and 5 outline the respective mean scores for willingness to refer oneself between males versus females and between those who have previous EAP usage versus those who have never used the EAP.

See Tables $3,4 \& 5$ on pages 17A, 17B \& 17C

\section{Tests of Hypotheses}

Hypothesis 1 which attempted to confirm the Harris et al. results that embarrassment, trust, attention, control, familiarity, effectiveness and referral by supervisor would be significant predictors of willingness to self refer for an alcohol abuse problem was mainly supported. A multiple regression analysis was conducted in 
Referral 17A

Table 3

Mean willingness to refer to an EAP for employees and supervisors by referral reason

\begin{tabular}{lllllll}
\hline & \multicolumn{3}{c}{ Employees } & Supervisors & \multicolumn{3}{c}{ Overall } \\
& & & & & & \\
\cline { 2 - 7 } Referral reason & $\underline{\mathrm{M}}$ & $\underline{\mathrm{SD}}$ & $\underline{\mathrm{M}}$ & $\underline{\mathrm{M}}$ & $\underline{\mathrm{M}}$ & $\underline{\mathrm{SD}}$ \\
\hline Alcohol abuse & 3.81 & 1.60 & 4.86 & 1.25 & 4.23 & 1.29 \\
Drug abuse & 3.75 & 1.56 & 4.64 & 1.14 & 4.17 & 1.43 \\
Psychological & 3.46 & 1.66 & 4.19 & 1.15 & 3.80 & 1.48 \\
Financial & 3.47 & 1.16 & 4.33 & 1.27 & 3.88 & 1.28 \\
Career & 3.59 & 1.42 & 4.45 & 1.09 & 4.00 & 1.34 \\
Family & 3.89 & 1.17 & 4.67 & 1.08 & 4.26 & 1.19 \\
\hline
\end{tabular}

Note: Willingness to refer ranges from 1 to 6 
Referral 17B

Table 4

Mean willingness to refer to an EAP for males and females by referral reason

\begin{tabular}{lllll}
\hline & \multicolumn{2}{c}{ Males } & Females \\
& & & & \\
\cline { 2 - 5 } Referral reason & $\underline{\mathrm{SD}}$ & $\underline{\mathrm{S}}$ & $\underline{\mathrm{SD}}$ \\
& & & & \\
\hline Alcohol abuse & 4.24 & 1.52 & 4.21 & 1.49 \\
Drug abuse & 4.19 & 1.43 & 4.15 & 1.46 \\
Psychological & 3.64 & 1.55 & 3.97 & 1.40 \\
Financial & 3.61 & 1.25 & 4.30 & 1.21 \\
Career & 3.73 & 1.41 & 4.18 & 1.26 \\
Family & 4.11 & 1.17 & 4.42 & 1.20 \\
& & & & \\
\hline
\end{tabular}

Note: Willingness to refer ranges from 1 to 6 
Referral $17 \mathrm{C}$

Table 5

Mean willingness to self refer to an EAP for no prior EAP usage and prior EAP usage by referral reason

\begin{tabular}{lllll}
\hline & \multicolumn{2}{c}{ Not used EAP } & \multicolumn{2}{c}{ Used EAP } \\
\cline { 2 - 5 } Referral reason & $\underline{\mathrm{M}}$ & $\underline{\mathrm{SD}}$ & $\underline{\mathrm{M}}$ & $\underline{\mathrm{SD}}$ \\
\hline Alcohol abuse & 3.58 & 1.50 & 5.06 & 1.00 \\
Drug abuse & 3.54 & 1.37 & 5.00 & 1.05 \\
Psychological & 3.26 & 1.52 & 4.50 & 1.11 \\
Financial & 3.63 & 1.21 & 4.68 & 0.94 \\
Career & 3.46 & 0.94 & 4.24 & 1.21 \\
Family & 3.72 & 0.85 & 4.94 & 0.85 \\
\hline
\end{tabular}

Note: Willingness to refer ranges from 1 to 6 
an effort to confirm the results of the Harris et al. (1988) study. Willingness to self refer to an EAP for an alcohol abuse problem was regressed on the seven predictor variables of effectiveness, embarrassment, attention, trust, control, familiarity and referral by supervisor (see Table 6). The amount of variance accounted for in willingness to self refer to an EAP for an alcohol abuse problem by the employees' attitudes towards the EAP was significant $\left(\underline{R}^{2}=.78, \underline{F}(7,26)=12.01, \underline{p}<.01\right)$. Specific significant effects were found for attention $(\underline{b}=.50, \underline{t}=4.03, \underline{p}<.01)$, control $(\underline{b}=.45, \underline{t}$ $=3.65, \underline{\mathrm{p}}<.01)$ and embarrassment $(\underline{\mathrm{b}}=.29, \underline{\mathrm{t}}=-2.89, \underline{\mathrm{p}}<.01)$ for one's willingness to self refer to an EAP for an alcohol abuse problem (see Table 6).

Multiple regression analyses were also performed to examine willingness to self refer to an EAP for drug, psychological, career, financial and family problems. Willingness to self refer to an EAP for each problem was regressed on employees' attitudes towards the EAP. Table 6 details the specific findings from each regression equation. To start with, the amount of variance accounted for in willingness to self refer to an EAP for a drug abuse problem by the employees' attitudes towards the EAP was significant $\left(\underline{R}^{2}=.88, \underline{F}(7,27)=29.98, \underline{p}<.01\right)$. Specific significant effects were found for trust $(\underline{b}=35, \underline{t}=3.19, \underline{p}<.01)$, control $(\underline{b}=.59, \underline{t}=7.09, \underline{p}<.01)$ and referral $(\underline{b}=31$, $\underline{t}=2.78, \mathrm{p}<.01$ ) for one's willingness to self refer for a drug abuse problem (see Table 6). Next, the amount of variance accounted for one's willingness to self refer to an EAP for a psychological problem by their attitudes towards the EAP was also significant $\left(\underline{R}^{2}=86, \underline{F}(7,28)=24.61, p<.01\right)$ with significant effects for referral $(\underline{b}=.43$, $\underline{\mathrm{t}}=2.63, \underline{\mathrm{p}}<.01)$, control $(\underline{\mathrm{b}}=.54, \underline{\mathrm{t}}=5.00, \underline{\mathrm{p}}<.01)$ and trust $(\underline{\mathrm{b}}=.49, \underline{\mathrm{t}}=4.07, \mathrm{p}<.01)($ see Table 6). Likewise, multiple regression analysis for one's willingness to self refer for a career problem was significant $\left(\underline{R}^{2}=.80, \underline{F}(7,27)=15.90, \underline{p}<.01\right)$ (see table 6). Specific 
significant effects were found for effectiveness $(\underline{b}=.52, \underline{t}=3.75, \underline{p}<.01)$ and referral $(\underline{b}=.72, \underline{t}=6.30, \underline{p}<.01)$ for one's willingness to self refer for career related problems (see Table 6). Next, the amount of variance accounted for in willingness to self refer to an EAP for financial problems was also found to be significant $\left(\underline{R}^{2}=79, \underline{F}(7,27)=14.61\right.$, $\underline{p}<.01)$ with specific significant effects for referral $(\underline{b}=.76, \underline{t}=8.83, \underline{p}<.01)$ and control $(\underline{b}=32, \underline{t}=3.72, \underline{p}<.01)$ (see Table 6). Finally, the amount of variance accounted for willingness to self refer for family related problems was significant $\left(\underline{R}^{2}=.85\right.$, $\underline{F}(7,27)=21.62, \underline{p}<.01)$. Specific significant effects were found for trust $(\underline{b}=.57, \underline{t}=4.63$, $\underline{\mathrm{p}}<.01)$, control $(\underline{\mathrm{b}}=.40, \underline{\mathrm{t}}=4.33, \underline{\mathrm{p}}<.01)$ and referral $(\underline{\mathrm{b}}=.43, \underline{\mathrm{t}}=5.01, \underline{\mathrm{p}}<.01)$ (see Table 6).

See Table 6 on page 19A

Hypothesis 2 attempted to show that employees would be more willing to self refer to an EAP for career, financial and family problems than for alcohol, drug and psychological problems. An ANOVA with repeated measures was used to analyze Hypothesis 2. The repeated measures were the willingness to self refer oneself for all six problems. Results for Hypothesis 2 were found not to be significant $(\underline{F}(1,34)=$ $0.96, \mathrm{p}>.05)$.

The comparison of supervisory versus self referrals to an EAP (Hypothesis 3) was supported. A MANOVA was used for analysis with likelihood to refer from supervisors and employees as independent variables and each of the six problems as dependent variables. Wilks $\Lambda(\underline{F}(1,65)=2.38, \underline{p}<.05)$ revealed that supervisors were significantly more willing to refer an employee to an EAP across all six problems as 
Table 6

Multiple regression analyses of attitudes towards EAP on willingness to self refer by type of problem

\begin{tabular}{|c|c|c|c|c|c|c|c|c|c|c|}
\hline \multirow[t]{2}{*}{ Problem } & \multirow[b]{2}{*}{$\underline{\mathrm{R}}^{2}$} & \multicolumn{2}{|c|}{ Attention } & Control & Embarrassment & Familiarity & \multicolumn{2}{|c|}{ Trust } & Effectiveness & Referral \\
\hline & & $\underline{B}$ & $\mathrm{p}$ & $\underline{p}$ & $\underline{\beta}$ & $\underline{\beta}$ & $\underline{\beta}$ & $\underline{p}$ & $\underline{B}$ & $\underline{\beta}$ \\
\hline Alcohol & .78 & .49 & .01 & $\begin{array}{ll}43 \quad .01\end{array}$ & .29 .01 & $.25 \quad .08$ & .08 & .41 & $.19 \quad .25$ & .14 .32 \\
\hline Drug & .88 & -.06 & .60 & .59 .01 & $.08 \quad .40$ & .05 .61 & .35 & .01 & -.01 .90 & .31 .01 \\
\hline Psych. & .86 & -.10 & .41 & $.54 \quad .01$ & -.10 .34 & -.01 .91 & .49 & .01 & .19 .11 & .43 .01 \\
\hline Career & .80 & -.08 & .69 & -.05 .67 & $.00 \quad .98$ & .13 .24 & .11 & .29 & $.52 \quad .01$ & .72 .01 \\
\hline Financial & .79 & .12 & .36 & $.32 \quad .01$ & -.16 .11 & -.02 .83 & .05 & .69 & -.11 .38 & .76 .01 \\
\hline Family & .85 & .09 & .54 & $.40 \quad .01$ & -.15 .19 & .09 .61 & .57 & .01 & $.11 \quad 43$ & . 43.01 \\
\hline
\end{tabular}

Note: All $\underline{\mathrm{R}^{2}}$ 's were significant at the .01 level 
compared to employee self referrals to an EAP. Further analyses using an oneway ANOVA for each of the six problem types revealed that all six problems discussed in the survey significantly differed when comparing self versus supervisory referrals to an EAP (see Table 7).

See Table 7 on page $20 \mathrm{~A}$

Similar to the analysis of employee self referrals (Hypothesis 1), willingness to give supervisory referrals for alcohol, drug, psychological, career, financial and family problems was regressed separately on the six predictor variables of effectiveness, embarrassment, attention, trust, control and familiarity. The amount of variance accounted for in willingness to give supervisory referrals by the employees' attitudes towards the EAP was highly significant for each problem. Table 8 lists all the significant findings from the multiple regression analyses of supervisors' willingness to refer employees to an EAP.

First, the amount of variance accounted for in willingness to give supervisory referrals to an EAP for an alcohol abuse problem by the supervisors' attitude towards the EAP was significant $\left(\underline{R}^{2}=.76, \underline{F}(6,24)=13.19, \underline{p}<.01\right)$ (see Table 8). Significant effects were also found for trust $(\underline{b}=.45, \underline{t}=3.68, \underline{p}<.01)$ and control $(\underline{b}=.56, \underline{t}=3.51$, $\underline{p}<.01$ ) for one's willingness to give a supervisory referral to an EAP for an alcohol abuse problem. For drug abuse, the amount of variance accounted for in willingness to give supervisory referrals to an EAP by the supervisors' attitude towards the EAP was also significant $\left(\underline{R}^{2}=.56, \underline{F}(6,24)=5.11, \underline{p}<.01\right)$ with significant effects found for effectiveness $(\underline{b}=.35, \underline{t}=2.13, \underline{p}<.01)$ and control $(\underline{b}=.51, \underline{t}=4.75, \underline{p}<.01)$ (see Table 8). 
Referral 20A

Table 7

Univariate ANOVA results of self versus supervisory referrals to an EAP by referral reason

\begin{tabular}{llll} 
Referral reason & $\underline{\mathrm{df}}$ & $\underline{\mathrm{F}}$ & $\mathrm{p}$ \\
\hline Alcohol abuse & 1,69 & 6.40 & 0.01 \\
Drug abuse & 1,67 & 7.17 & 0.01 \\
Psychological & 1,67 & 4.35 & 0.04 \\
Financial & 1,67 & 8.70 & 0.01 \\
Career & 1,68 & 7.90 & 0.01 \\
Family & 1,68 & 8.19 & 0.01 \\
& & & \\
\hline
\end{tabular}


Referral 21

Next, the amount of variance accounted for in willingness to give supervisory referrals to an EAP for a psychological problem by the supervisors' attitude towards the EAP was similarly found to be significant $\left(\underline{R}^{2}=49, \underline{F}(6,23)=3.63, \underline{p}<.01\right)$ (see Table 8).

Furthermore, a significant effect was found for effectiveness $(\underline{b}=.43, \underline{t}=2.65, \underline{p}<.01)$ for one's willingness to give a supervisory referral to an EAP for a psychological problem (see Table 8). In addition, the amount of variance accounted for in willingness to give supervisory referrals to an EAP for career related problems by the supervisors' attitude towards the EAP was likewise significant $\left(\underline{R}^{2}=.60, \underline{F}(6,24)=6.57, \underline{p}<.01\right)$ with a significant effect found for effectiveness $(\underline{b}=.47, \underline{t}=2.18, \underline{p}<.05)$. For financial problems, the amount of variance accounted for in willingness to give supervisory referrals by the supervisors' attitude towards the EAP was significant also $\left(\underline{R}^{2}=.51\right.$, $\underline{F}(6,24)=4.98, \underline{p}<.01)$. Significant effects were found for effectiveness $(\underline{b}=.32, \underline{t}=3.62$, $\underline{\mathrm{p}}<.01)$ and control $(\underline{\mathrm{b}}=.64, \underline{\mathrm{t}}=6.43, \underline{\mathrm{p}}<.01)$ for supervisor's willingness to refer to an EAP for financial problems. Finally, a multiple regression analysis examining supervisory referrals for family related problems was also significant $\left(\underline{R}^{2}=.72\right.$, $\underline{F}(6,24)=12.71, \underline{p}<.01)$ along with significant effects found for effectiveness $(\underline{b}=.53$, $\underline{\mathrm{t}}=3.58, \underline{\mathrm{p}}<.01)$ and attention $(\underline{\mathrm{b}}=.32, \underline{\mathrm{t}}=2.16, \underline{\mathrm{p}}<.05)$.

See Table 8 on page $21 \mathrm{~A}$

Hypothesis 4, which stated that women would be significantly more willing than men to self refer to an EAP, was not found to be significant at the 0.05 level. A MANOVA was used for analysis with likelihood to refer for men and women as independent variables and each of the six problem types as dependent variables. Wilks 
Table 8

Multiple regression analyses of attitudes towards EAP on supervisors' willingness to refer employees to an EAP by type of problem

\begin{tabular}{|c|c|c|c|c|c|c|c|c|c|c|c|c|c|}
\hline \multirow[t]{2}{*}{ Problem } & \multirow[b]{2}{*}{$\underline{\mathrm{R}^{2}}$} & \multicolumn{2}{|c|}{ Attention } & \multicolumn{2}{|c|}{ Control } & \multicolumn{2}{|c|}{ Embarrassment } & \multicolumn{2}{|c|}{ Familiarity } & \multicolumn{2}{|c|}{ Trust } & \multicolumn{2}{|c|}{ Effectiveness } \\
\hline & & $\underline{\beta}$ & $\mathbf{p}$ & $\underline{\beta}$ & $\underline{p}$ & $\underline{\beta}$ & p & $\underline{\beta}$ & $\mathrm{p}$ & $\underline{\beta}$ & $\underline{p}$ & $\underline{\beta}$ & p \\
\hline Alcohol & .76 & .09 & .54 & .56 & .01 & .18 & .15 & .08 & .43 & .45 & .01 & .14 & .31 \\
\hline Drug & .56 & .16 & .21 & .51 & .01 & .14 & .26 & .19 & .11 & .09 & .37 & .35 & .01 \\
\hline Psych. & .49 & .20 & .54 & .06 & .80 & -.08 & .61 & .10 & .51 & .06 & .79 & .43 & .01 \\
\hline Career & .60 & .24 & .15 & .25 & .21 & -.01 & .92 & -.02 & .84 & .16 & .33 & .47 & .04 \\
\hline Financial & .51 & .12 & .38 & .64 & .01 & -.05 & .66 & .05 & .54 & .02 & .88 & .32 & .01 \\
\hline Family & .72 & .32 & .04 & .03 & .82 & .04 & .68 & .03 & .76 & .05 & .78 & .53 & .01 \\
\hline
\end{tabular}

Note: All $\underline{\mathrm{R}}^{2}$ 's were significant at the .01 level 
$\Lambda(\underline{F}(1,34)=2.04, p=.09)$ revealed that women did not significantly differ from men in willingness to self refer across all six problems in willingness to self refer to an EAP.

Finally, exploratory research disclosed that there was a significant difference in responses between those who have previously used the EAP and those who have not used the EAP on willingness to self refer. A MANOVA was used for analysis with likelihood to self refer to an EAP from those who have previously used the EAP and those who have never used the EAP as independent variables and each of the six problems as dependent variables. Wilks $\Lambda(\underline{F}(1,33)=4.55, \underline{p}<.005)$ indicated that employees who have previously used the EAP were significantly more willing to self refer to an EAP across all six problems as compared to those employees who have never used the EAP. Follow up analyses using oneway ANOVA's for each of the six problem types revealed that each problem type was also individually significant in comparing willingness to self refer between those who have used the EAP and those who have not (see Table 9).

See Table 9 on page 22A

\section{Discussion}

\section{Implications of Results}

The attempt to predict employees' willingness to self refer to an EAP (Hypothesis 1a) was quite effective. The results backed up the findings from the Harris et al. (1988) study by using the employees' attitudes towards the EAP in predicting employees' willingness to self refer for an alcohol abuse problem. However, Harris et al. found that trust, attention and familiarity were the significant predictors of respondents' 
Referral $22 \mathrm{~A}$

Table 9

Univariate ANOVA results of previous EAP usage versus non usage by referral reason

\begin{tabular}{llll}
\hline Referral reason & $\underline{\mathrm{df}}$ & $\underline{\mathrm{F}}$ & $\underline{\mathrm{p}}$ \\
\hline Alcohol abuse & 1,69 & 22.72 & 0.01 \\
Drug abuse & 1,67 & 23.40 & 0.01 \\
Psychological & 1,67 & 14.29 & 0.01 \\
Financial & 1,67 & 4.09 & 0.05 \\
Career & 1,68 & 17.63 & 0.01 \\
Family & 1,68 & 24.25 & 0.01 \\
\hline
\end{tabular}


willingness to participate in an EAP. This study determined that attention, control and embarrassment were significant predictors. The two studies reached similar results for attention, but differed on the other two variables. It is important to consider the findings from both studies when examining issues related to willingness to self refer to an EAP. One should focus on the issues of attention, familiarity, trust, embarrassment and control when examining factors that influence employees' decisions to self refer to an EAP for an alcohol abuse problem.

In addition, this study went beyond Harris et al. (1988) by examining issues other than just willingness to refer oneself to an EAP due to alcohol abuse. Likewise, Hall et al. (1991) examined additional problems other than alcohol abuse but used a different set of predictors to do so. An stated earlier, one of the goals of this study was to combine aspects of both previously mentioned studies; by using the notion of analyzing multiple problems (Hall et al.) and by using the seven predictor variables from Harris et al. Hypotheses $1 \mathrm{~b}-1 \mathrm{f}$ were each proven to be significant in using the seven predictor variables as predictors of willingness to self refer to an EAP for drug, psychological, career, financial and family problems. The significant results illustrated how effective the collective usage of the predictor variables of familiarity, embarrassment, attention, effectiveness, trust, control and referral by supervisor can be in predicting employee willingness to self refer to an EAP for a variety of personal problems. The implications of these findings are that the employees' attitudes towards the EAP can be used to predict more than just willingness to self refer to an EAP for an alcohol abuse problem, but also can be used to predict willingness to self refer to an EAP for a variety of potential problems such as drug, psychological, career, financial and family problems. 
Further investigations revealed that specifically the predictor variables of control, trust and referral by supervisor appeared to be significant throughout the analyses (see Table 6). All three were significant for drug, psychological and family problems and at least one of the three predictors were significant for the remainder of the problems studied (alcohol, career and financial). These findings suggested that perhaps the respondents were concerned more about job security concerns rather than personal health concerns when making a decision to use the EAP. Particularly, trust and referral by supervisor do not directly reflect the subject's knowledge or opinion if they believe the EAP will help them or not with a problem, but it does reflect their concerns about how the company will view them. For example, the results indicated if an employee had a hypothetical drug abuse problem, he/she would be willing to use the EAP if his/her supervisor recommended it and/or if the information discussed in the EAP sessions were kept confidential from the employer. Furthermore, the results indicated that these two reasons would be more important to an employee in deciding to receive help than would using the EAP because he/she is familiar with the program or because he/she thinks it would be effective in solving his/her problem. This idea should be investigated further in future research. It would be of interest to know if employees' willingness to self refer to an EAP is influenced more by job security concerns or personal health concerns and if it varies by organization.

As the results of Hypothesis 2 implied, it does not appear that the type of problem has an effect on the respondents' willingness to self refer to an EAP. Scanlon (1986) had suggested that people may vary in their use of an EAP depending on the problem. Scanlon felt the more severe or potentially embarrassing the problem was to the employee, such as alcohol, drug and psychological problems, the less likely the 
employee would be willing to use the EAP. There were no significant differences when comparing the type of problem to willingness to self refer to an EAP. This suggests that for the subjects in the study the type of problem does not affect one's willingness to self refer to an EAP, but with the low response rate, it is uncertain if this can be generalized to all employees in other organizations.

Hypothesis 3 was supported. Results strongly indicated that there was a significant difference between supervisory and self willingness to refer such that supervisors were more willing to refer across all six problems. This has a couple of implications for this organization. First, because supervisors are more willing to refer employees, they should be trained properly to recognize distressed workers in order to avoid "false positives". For instance, if a supervisor refers an employee to an EAP and it turns out the employee did not have a problem, this could lead to issues of distrust between the employee and the organization, not to mention higher costs to the company for the cost of the unneeded EAP sessions. The employee might not feel comfortable working for an employer that insinuates he/she is a distressed worker. A second ramification might result from employees not wanting to resolve their problems through the means of using a company sponsored service. The answer to this issue lies within this study. Companies need to focus on issues that are important to employees in order to improve the usage of EAP's. For example, trust in the confidentiality of the EAP was shown to be a significant predictor of willingness to self refer. Consequently, companies must focus on insuring their employees that the EAP will keep all information confidential in order to increase the usage of their EAP.

In addition, analyses indicated that supervisors differed from employees in their motivation for making referrals. Table 10 summarizes the specific findings of the 
analyses for self and supervisory referrals. As stated earlier, employees viewed control, trust and referral by supervisor as the key predictors of willingness to self refer to an EAP. As Table 10 shows, supervisors also viewed control as a key predictor of their willingness to refer employees to an EAP, however they additionally perceived effectiveness of the EAP as a major factor in their willingness to refer employees. Employees, except for career problems, did not consider effectiveness of the EAP when making a referral decision. This result implied that supervisors in this study examined the actual capability of the EAP to resolve employee problems when deciding to make a referral decision whereas employees were more concerned about their job security when deciding to self refer to an EAP. This is an idea that has not been previously studied in the literature. Future study should be pursued to examine if this is valid; do supervisors rely more on the effectiveness of the EAP to make referrals whereas employees use more job security concerns in determining their willingness to self refer to an EAP?

See Table 10 on page $26 \mathrm{~A}$

Next, Hypothesis 4 was found not to be significant. Gender did not affect one's willingness to self refer to an EAP. As mentioned previously in this study, there was some debate in the past over this issue. Trice and Breyer (1979) concluded that men and women react differently in their use of EAP's. They determined women would be more willing to seek help for a problem. To add to that, Good (1989) and Leaf (1987) concluded that men were less likely to seek help in fear they may appear weak if they sought professional assistance for a problem. Conversely, the Harris et al. (1988) study 
Referral 26A

Table 10

Summary of significant predictors for willingness to self refer and supervisory referral to an EAP by type of problem

Significant Predictors

Problem Self Referrals $\quad$ Supervisory Referrals

$\begin{array}{lll}\text { Alcohol } & \text { attention, control, embarrassment } & \text { trust, control } \\ \text { Drug } & \text { control, trust, referral } & \text { effectiveness, control } \\ \text { Psych. } & \text { control, trust, referral } & \text { effectiveness } \\ \text { Career } & \text { referral, effectiveness } & \text { effectiveness } \\ \text { Financial } & \text { control, referral } & \text { effectiveness, control } \\ \text { Family } & \text { control, trust, referral } & \text { effectiveness, attention }\end{array}$


examined this issue, but found no differences between men and women. Once again, this study elicited results similar to the Harris et al. study. Gender did not affect willingness to self refer. Organizations should take this as good news. There appears to be no need for an organization to focus more on one specific sex than the other to encourage EAP usage.

Finally, exploratory research reached meaningful findings when comparing those who had previous EAP experience to those who had not. Previous literature has not examined whether prior EAP experience would affect future EAP usage. Results indicated that there was a major difference in willingness to refer to an EAP between those who had used the EAP and those who had no prior EAP experience (see Tables 5 and 9). The findings disclosed that employees surveyed in this study who have had previous EAP experience were more willing to use the EAP in the future than employees with no prior EAP experience. This suggests that the employees in this study who have used the EAP in the past do not view it as something negative. If they had negative experiences in the past, they would have most likely reported less willingness to self refer to the EAP as compared to those employees who have never used the EAP (Hall et al., 1990). For this study, the organization should view this finding as something positive in that prior EAP experience favorably affects future usage. However, this finding may be specific to the organization and the EAP used in this study. Future research should be conducted to investigate if this result can be generalized to other organizations and to other employee assistance programs.

\section{Limitations}

One possible shortcoming to this study was the fact that 30 out the 71 subjects have used the EAP in the past. This could be considered a shortcoming to the study 
because of the 600 employees at the company surveyed, only approximately 90 had used the EAP previously. This translates into only $8 \%$ of the workforce who have not used the EAP in the past filled out a survey while $33 \%$ of the workforce who have used the EAP in the past elected to fill out a survey. The results obtained from this study might be so convincing because a fair proportion of the people who completed the survey have experience with the EAP. It was hoped that more employees would have completed the survey, especially those who have not used the EAP in the past. The overall response rate to this survey was only $11.83 \%$. The goal of the study was to have at least a $25 \%$ response rate in order to obtain a full representation of the organization. Perhaps employees did not have enough trust that their information would be kept confidentially. One reason for this might be the result of having a human resources employee administer the survey to the employees. Employees might have been more willing to participate in the study if someone from outside of the organization administered the survey to them. Future research should look for ways to increase the participation rate of surveys on EAP usage.

Another possible limitation to this study is limited generalizability of the results. The results were strong, but were they only specific to this organization and to this EAP? For example, results indicated that employees were concerned about job security issues when deciding to self refer to the EAP. The organizational climate where this survey was conducted might be such that employees feel their jobs are in jeopardy unless they do "what the company wants them to do." Would this finding be similar in other organizations? Furthermore, the EAP used in this study might have affected the results. For example, results clearly showed that employees with previous EAP experience were willing to use the EAP in the future. Can this finding be generalized to 
all EAP's or is the EAP used in this study better than others? This study should be replicated in other organizations (both public and private) to determine if these findings are only specific to this company or if they can be generalized to all types of organizations, industries and EAP's.

\section{Future Study}

There are four important issues that resulted from this study that should require future research. First, the question of whether employees' consider job security concerns more than personal concerns when deciding to self refer to an EAP should be investigated in more detail. This result was not expected in this study. It would be informative if future studies attempted to validate this finding. If the finding is true, then there should also be further analyses to ascertain why this is happening. For example, are employees more concerned about keeping their job over receiving help to resolve a problem?

Second, this study found that supervisors focus more on the actual effectiveness of the EAP when deciding to make referrals, whereas employees focus more on job security concerns when making self referrals. This difference between factors affecting supervisory versus self referrals was also not expected. Future research should additionally examine if there is a difference in the decision making process between supervisory and self referrals. If there is such a difference, research should also find out why this difference exists.

Next, this study should be replicated in other organizations and industries. This survey took place in a government agency and the results might be different if it was administered in a private organization. Therefore, It is important to discover if these 
meaningful findings are specific to this particular organization or if they can be generalized to all employees in a variety of industries.

Finally, future research should attempt to involve more employees who have not used the EAP. As mentioned earlier, a possible limitation to this study was that a low percentage of employees who have never used the EAP participated in this study. As a result, this could explain why findings such as comparing those who have used the EAP to those who have not were so convincing. Future studies should attempt to survey those who have never used the EAP to determine what factors will improve their likelihood to self refer to an EAP.

\section{Final Conclusions}

In conclusion, there were important findings that resulted from this study. First, this study largely confirmed the results from the Harris et al. (1988) study by using the seven employee attitudes towards the EAP variables in predicting willingness to self refer to an EAP for an alcohol abuse problem. This study went beyond Harris et al. by also examining these variables with other problems. It was found that the seven employee attitudes towards the EAP were quite effective in predicting willingness to self refer to an EAP for all types of problems. Furthermore, it was discovered that the type of problem did not have an effect on one's willingness to self refer to an EAP.

It was also established that there was a significant difference for those who participated in this study between supervisory and self referrals to an EAP such that supervisors were more willing to refer across all six problems. This issue had not been previously investigated. Furthermore, it was suggested that there was a difference between employees and supervisors in factors related to willingness to refer to an EAP. The primary difference was that supervisors looked more at the overall effectiveness of 
the EAP program when deciding willingness to refer employees while employees looked more at job security concerns, such as referral by supervisor or trust in confidentiality, when deciding willingness to self refer to an EAP. This was an important finding. Research had been non-existent in examining this issue. Future research should investigate this issue further to examine if this conclusion can be generalized to other organizations.

Moreover, the results that the employees' surveyed take into account job security concerns when deciding willingness to self refer to an EAP ties back to the model for examining EAP utilization (see Figure 1) discussed in the Hall et al. (1991) study. This model emphasized the notion that organizational factors, such as trust, referral by supervisor and use of EAP to keep job, directly relate to one's propensity to use an EAP. The results of this study affirmed this notion. Employees in this study did consider these organizational factors when deciding to self refer to an EAP.

In addition, it was found that men and women in this study did not differ in willingness to self refer to an EAP. Finally, the exploratory research illustrated that employees in this survey who have used the EAP in the past would be willing to use it in the future if the situation was needed. This comes back to the central theme of this study; factors influencing willingness to use an EAP. If organizations focus on factors that increase EAP usage, such as supervisory referrals, trust, control and effectiveness, there would be enhanced likelihood the EAP would be used by more employees. This study commenced by mentioning that $20 \%$ of employees could be classified as being "distressed", but only $7 \%$ of employees take advantage of the EAP offered to them. If organizations focus on the important issues previously mentioned in this study, this gap of $13 \%$ could be reduced. 


\section{References}

Bruan, A. \& Novak D.(1986). A study of EAP non-utilization. EAP Digest, $\underline{7}$, 52-55.

Breyer, J. \& Trice, H. (1978). Implementing change: alcoholism policies in work organizations. New York: The Free Press. .

Costello, J. (1987). Employee assistance programs and clinical social work in America: A developmental perspective. Journal of Social Work Practice, 2, 4, 114-127.

Dixon, K. (1988). Employee assistance programs: a primer for buyer and seller. Hospital and Community Psychiatry, $\underline{39}, \underline{6}, 623-627$.

Dooley, S. \& Macdonald, S. (1990). Employee assistance programs: Emerging trends. Canadian Journal of Community Mental Health, $\underline{9}, \underline{1}, 97-105$.

Fizek, L. \& Zare N. (1988). Factors affecting referrals from employee assistance programs to community agencies. Employee Assistance Quarterly, $4,2,31-43$.

Gam, J., Sauser, W, Eavan, E. \& Lair, C. (1983). Evolution of an employee assistance program. Journal of Employment Counseling, 20, 99-106.

Gerstein, L., Gaber, T., Daines, C., \& Duffy, K. (1993). Organizational hierarchy, employee status, and use of employee assistance programs. Journal Employment Counseling $30,2,74-78$.

Good, G. (1989). Male role and gender role conflict: Relations to help seeking in men. Journal of Counseling Psychology, 36, $\underline{3}, 295-301$.

Hall, L., Vacc, M. \& Kissling, G. (1991). Likelihood to use employee assistance programs. Journal of Employment Counseling, 28, 63-73. 
Harris, M. \& Fennell, M. (1988). Perceptions of an employee assistance program and employees' willingness to participate. The Journal of Applied Behavioral Sciences, $\underline{24}, \underline{4}, 423-438$.

Johnson, A. (1985). Municipal employee assistance programs: Managing troubled employees. Public Administration Review, 45, 383-388.

Keohane, R. \& Newman, C. (1984). A family agency's approach to providing employee assistance programs to industry. Social Work, 29, 295-298.

LaRock, S. (1984). Defense departments sets up employee assistance. Employee Benefit Plan Review, 39, 57-63.

Leaf, P. (1987). Gender differences in the use of mental health related services: A re-examination. Journal of Health and Social Behavior, $\underline{28}, \underline{2}, 171-183$.

Lovato, C. \& Green, L. (1990). Maintaining employee participation in workplace health promotion programs. Health Education Quarterly, 17, 1 , 73-80.

Luthans, J. \& Waldersee M. (1988). Managerial influence in the implementation of new technology. Managerial Science, 34, 252-265.

Milne, S., Blum, T., \& Roman, P. (1994). Factors influencing employees' propensity to use an employee assistance program. Personnel Psychology, 47, 123135 .

Scanlon, L.(1986). Designing Effective Employee Assistance Programs. New York: Quantum Books.

Smith, D. \& Mahoney, J. (1989). McDonnell Douglas Corporation: Employee assistance program financial offset study 1985-1988. Alexander and Alexander Counseling Group. 
Trice, A., Haire, J. \& Elliot, K. (1989) A career locus of control scale for undergraduate students. Perceptual and Motor Skills, 69, 2 , 555-561.

Webb, W. (1991). Resistant employees: Implications for EAP counselors.

Employee Assistance Quarterly, 7, 1, 9-18.

Wegener, N. (1992). Supportive group services in the workplace: The practice and the potential. Social Work with Groups, 15, 2-3, 207-222. 
Appendix A

Employees' Survey

PLEASE CIRCLE THE APPROPRIATE CHOICE.

\begin{tabular}{|c|c|}
\hline $\begin{array}{l}1 \text { - Strongly Disagree } \\
2=\text { Disagree } \\
3=\text { Slightly Disagree }\end{array}$ & $\begin{array}{l}4=\text { Slightly Agree } \\
5=\text { Agree } \\
6=\text { Strongly Agree }\end{array}$ \\
\hline
\end{tabular}

1. I am familiar with the Employee Assistance Program (EAP) in treating alcohol abuse problems provided by my work:

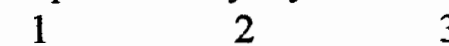

strongly disagree
3

4 $\begin{array}{lc}5 & 6 \\ & \text { strongly agree }\end{array}$

2. I would feel embarrassment if I attended the EAP provided by my work for an alcohol abuse problem:

$$
12
$$

strongly disagree
3

4
56

strongly agree

3. I would feel the EAP provided by my work would give me the appropriate attention that I would need to treat an alcohol abuse problem:

$\begin{array}{cccccc}1 & 2 & 3 & 4 & 5 & \begin{array}{c}6 \\ \text { strongly disagree }\end{array} \\ \text { strongly agree }\end{array}$

4. I would feel that the EAP provided by my work would NOT try to take total control of my daily routine if $I$ attended it for an alcohol abuse problem:
1
2
3
strongly disagree
56
strongly agree

5. I would have trust in the EAP provided by my work to keep any information about me confidential if I attended it for an alcohol abuse problem:
1
2
3
4
5
6
strongly agree

strongly disagree 
Referral 36

6. I perceive the EAP provided by my work as being effective in treating alcohol abuse problems:

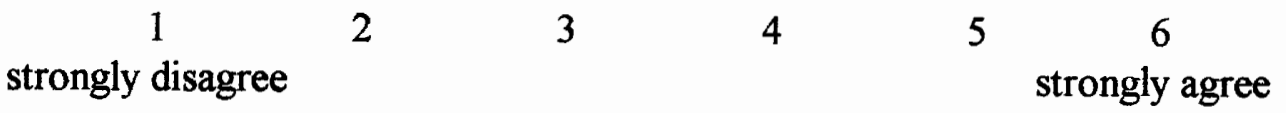

7. If my supervisor recommended that I attend the EAP provided by my work because he/she felt I had an alcohol abuse problem, I would attend the EAP:

strongly disagree

456

strongly agree

8. If I had an alcohol abuse problem, I would attend the EAP provided by my work:
1
2
3
4
5
6
strongly agree

strongly disagree

9. I am familiar with the Employee Assistance Program (EAP) provided by my work in treating drug abuse problems:
1
2
3
4
5
6
strongly agree

strongly disagree

10. I would feel embarrassment if I attended the EAP provided by my work for a drug abuse problem:

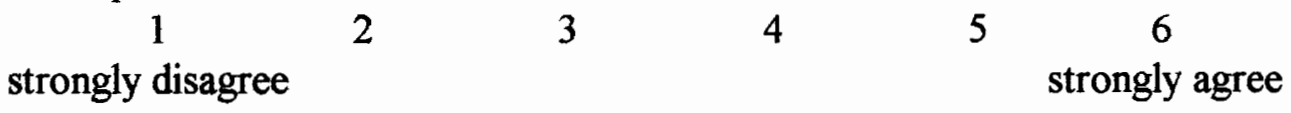

11. I would feel the EAP provided by my work would give me the appropriate attention that I would need to treat a drug abuse problem:

$\begin{array}{ccccccc}1 & 2 & 3 & 4 & 5 & \begin{array}{c}6 \\ \text { strongly agree }\end{array} \\ \text { strongly disagree } & & & & & & \end{array}$

12. I would feel that the EAP provided by my work would NOT try to take total control of my daily routine if I attended it for a drug abuse problem:

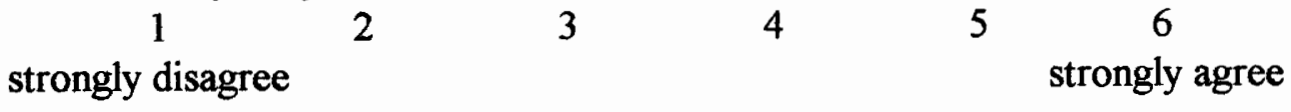


13. I would have trust in the EAP provided by my work to keep any information about me confidential if I attended it for a drug abuse problem:

strongly disagree

$2 \quad 3 \quad 4$

3

problem:

14. I perceive the EAP provided by my work as being effective in treating drug abuse problems:
12
34
4
56

strongly disagree

strongly agree

15. If my supervisor recommended that I attend the EAP provided by my work because he/she felt I had a drug abuse problem, I would attend the EAP:
1
2
3
4
56

strongly disagree

strongly agree

16. If I had a drug abuse problem, I would attend the EAP provided by my work:
1
2
3
4
5
6
strongly agree

strongly disagree

17. I am familiar with the EAP provided by my work in assisting with career problems, such as lack of job satisfaction or conflict with a coworker:

$\begin{array}{ccccccc}1 & 2 & 3 & 4 & 5 & \begin{array}{c}6 \\ \text { strongly agree }\end{array} \\ \text { strongly disagree } & & & & & & \end{array}$

18. I would feel embarrassment if I attended the EAP provided by my work for career problems:
1
2
3
4
5
6
strongly agree

strongly disagree

19. I would feel the EAP provided by my work would give me the appropriate attention that I would need to deal with my career problems:
1
2
3
4

\section{5}

strongly disagree

6

strongly agree 
20. I would feel that the EAP provided by my work would NOT try to take total control of my daily routine if I attended it to assist me with career problems:
1
2
3
4
5
6
strongly agree

strongly disagree

21. I would have trust in the EAP provided by my work to keep any information about me confidential if I attended it to assist me with career problems:

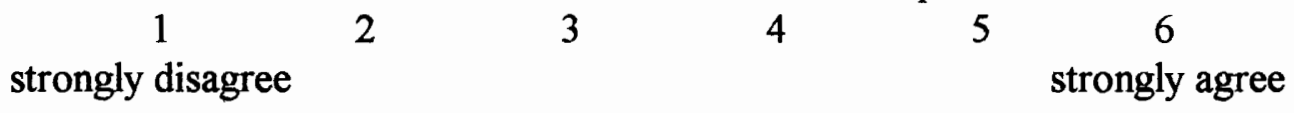

22. I perceive the EAP provided by my work as being effective in assisting employees with career problems:

1
strongly disagree

34

5

6

strongly agree

23. If my supervisor recommended that I attend the EAP provided by my work because he/she felt that I was experiencing career troubles, I would attend the EAP:
1
2
3
4
5
6
strongly agree

strongly disagree

24. I would attend the EAP provided by my work if I was experiencing career troubles:
12
3
4
5
6
strongly agree

strongly disagree

25. I am familiar with the EAP provided by my work in assisting with financial problems, such as ways to budget my money:
1
2
3
4
strongly disagree
5
strongly agree

26. I would feel embarrassment if I attended the EAP provided by my work for financial problems:

1

23

3

strongly disagree

$\begin{array}{ccc}4 & 5 & 6 \\ & & \text { strongly agree }\end{array}$ 
27. I would feel the EAP provided by my work would give me the appropriate attention that I would need to deal with any financial problems that I might have:

$$
\begin{array}{llllll}
1 & 2 & 3 & 4 & 5 & 6 \\
\text { strongly agree }
\end{array}
$$

strongly disagree

28. I would feel that the EAP provided by my work would NOT try to take total control of my daily routine if $I$ attended it to assist me with financial problems:

123

strongly disagree
4

5
6

strongly agree

29. I would have trust in the EAP provided by my work to keep any information about me confidential if $I$ attended it to assist me with financial problems:
1
2
3
4
5
6
strongly agree

strongly disagree

30. I perceive the EAP provided by my work as being effective in assisting employees with financial problems:
12
3
4
5
6
strongly agree

strongly disagree

31. If my supervisor recommended that I attend the EAP provided by my work because he/she felt that I was experiencing financial troubles, I would attend the EAP:

$\begin{array}{lllllc}1 & 2 & 3 & 4 & 5 & 6 \\ \text { strongly agree }\end{array}$

32. I would attend the EAP provided by my work if I was experiencing financial troubles:

$\begin{array}{cccccc}1 & 2 & 3 & 4 & 5 & 6 \\ \text { strongly disagree } & & & & & \text { strongly agree }\end{array}$

33. I am familiar with the EAP provided by my work in assisting with family problems, such as dealing with marital troubles:

$1 \quad 2 \quad 3$

strongly disagree
3

5

6

strongly agree 
Referral 40

34. I would feel embarrassment if I attended the EAP provided by my work for family problems:

1

strongly disagree
23

34

5

6

strongly agree

35. I would feel the EAP provided by my work would give me the appropriate attention that I would need to deal with any family problems that I might have:

$\begin{array}{llllll}1 & 2 & 3 & 4 & 5 & 6\end{array}$

strongly disagree strongly agree

36. I would feel that the EAP provided by my work would NOT try to take total control of my daily routine if I attended it to assist me with family problems:

strongly disagree

2

3

$5-6$

strongly agree

37. I would have trust in the EAP provided by my work to keep any information about me confidential if $I$ attended it to assist me with financial problems:
1
2
3
4

strongly disagree

strongly agree

38. I perceive the EAP provided by my work as being effective in assisting employees with family problems:

12

strongly disagree
23

$3-4$
5

strongly agree

39. If my supervisor recommended that I attend the EAP provided by my work because he/she felt that I was experiencing family troubles, I would attend the EAP:

12

strongly disagree
2
4$$
5
$$

5

strongly agree

41. I would attend the EAP provided by my work if I was experiencing family troubles:

1

strongly disagree

\section{2}

3

4

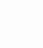
$5 \quad 6$ strongly agree


42. I am familiar with the EAP provided by my work in assisting with psychological problems, such as depression:
1
2
3
4
5
6
strongly agree

strongly disagree

43. I would feel embarrassment if I attended the EAP provided by my work for psychological problems:

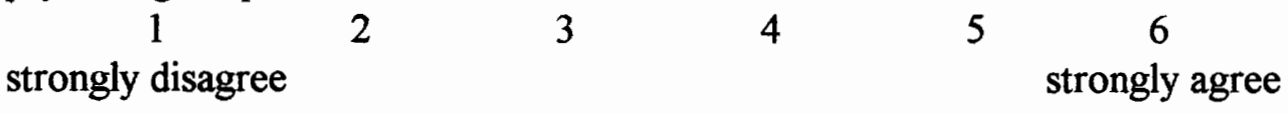

44. I would feel the EAP provided by my work would give me the appropriate attention that I would need to deal with any psychological problems that I might have:

1

2

strongly disagree
3
4
5 strongly agree

45. I would feel that the EAP provided by my work would NOT try to take total control of my daily routine if $I$ attended it to assist me with psychological problems:
1
2
3
4
5
6
strongly agree

strongly disagree

46. I would have trust in the EAP provided by my work to keep any information about me confidential if I attended it to assist me with psychological problems:

$\begin{array}{lllllll}1 & 2 & 3 & 4 & 5 & 6\end{array}$

strongly disagree

strongly agree

47. I perceive the EAP provided by my work as being effective in assisting employees with psychological problems:
1
2
3
4

5

6

strongly disagree

strongly agree 
48. If my supervisor recommended that I attend the EAP provided by my work because he/she felt that I was experiencing psychological troubles, I would attend the EAP:

$\begin{array}{lllllc}1 & 2 & 3 & 4 & 5 & 6 \\ \text { disagree } & & & & & \text { strongly agree }\end{array}$

49. I would attend the EAP provided by my work if I was experiencing psychological troubles:

$\begin{array}{cccccc}1 & 2 & 3 & 4 & 5 & 6 \\ \text { strongly disagree } & & & & & \\ \text { strongly agree }\end{array}$

Please answer the question in the space provided to the right

1. Gender: 1. Female 2. Male

2. Are you married? 1. Yes 2. No

3. Do you have children? 1. Yes 2. No

4. What is your age?

5. How many years have you worked at $\mathrm{r}$ current job?

6. Please state your level of education:

1. Less than high school

2. High school graduate

3. Some college

4. College degree

7. Have you ever used your company's EAP before? 1. Yes 2. No Appendix B 
Supervisors' Survey

\section{PLEASE CIRCLE THE APPROPRIATE CHOICE.}

\begin{tabular}{|lc}
\hline 1 = Strongly Disagree & $4=$ Slightly Agree \\
2 - Disagree & $5=$ Agree \\
3 - Slightly Disagree & 6 - Strongly Agree \\
\hline
\end{tabular}

1. I. am familiar with the Employee Assistance Program (EAP) provided by my work in treating alcohol abuse problems:

$1 \quad 2 \quad 3$

strongly disagree
4

$\begin{array}{cc}5 & 6 \\ & \text { strongly agree }\end{array}$

2. If I felt an employee had an alcohol abuse problem, and I recommended an employee to use the EAP provided by my work to deal with the problem, I would feel that employee would be embarrassed to attend the EAP:

$\begin{array}{llll}1 & 2 & 3 & 4\end{array}$

strongly disagree $\begin{array}{cc}5 & 6 \\ & \text { strongly agree }\end{array}$

3. If I felt an employee had an alcohol abuse problem, and I recommended an employee to use the EAP provided by my work to deal with the problem, I would feel the EAP would give the employee the appropriate attention that would be needed to treat an alcohol abuse problem:

$\begin{array}{cccccc}1 & 2 & 3 & 4 & 5 & 6 \\ \text { strongly disagree } & & & & & \text { strongly agree }\end{array}$

4. If I felt an employee had an alcohol abuse problem, and I recommended an employee to use the EAP provided by my work to deal with the problem, I would feel that the EAP provided by my work would NOT try to take total control of the daily routine of the employee to deal with the problem :

$\begin{array}{cccccc}1 & 2 & 3 & 4 & 5 & 6 \\ \text { strongly disagree } & & & & & \text { strongly agree }\end{array}$

5. If I felt an employee had an alcohol abuse problem, and I recommended an employee to use the EAP provided by my work to deal with the problem, I would have 
trust in the EAP provided by my work to keep any information about the employee confidential if they attended it:

$\begin{array}{llllll}1 & 2 & 3 & 4 & 5 & 6 \\ \text { strongly agree }\end{array}$

strongly disagree

6. I perceive the EAP provided by my work as being effective in treating alcohol abuse problems:

$\begin{array}{llllll}1 & 2 & 3 & 4 & 5 & 6\end{array}$

strongly disagree

strongly agree

7. If I felt an employee had an alcohol abuse problem, I would recommend that employee to use the EAP provided by my work to deal with the problem:

1

strongly disagree
23

4

strongly agree

8. I am familiar with the Employee Assistance Program (EAP) provided by my work in treating drug abuse problems:

12

strongly disagree
3

4

5

6

strongly agree

9. If I felt an employee had a drug abuse problem, and I recommended an employee to use the EAP provided by my work to deal with the problem, I would feel that employee would be embarrassed to attend the EAP:

12

strongly disagree
3
4

5

10. If I felt an employee had a drug abuse problem, and I recommended an employee to use the EAP provided by my work to deal with the problem, I would feel the EAP would give the employee the appropriate attention that would be needed to treat a drug abuse problem:
1
2
3
4
56
strongly agree

strongly disagree

11. If I felt an employee had a drug abuse problem, and I recommended an employee to use the EAP provided by my work to deal with the problem, I would feel that the EAP 
Referral 45

would NOT try to take total control of the daily routine of the employee to deal with the problem :

1

strongly disagree
23

4

5

6

strongly agree

12. If I felt an employee had a drug abuse problem, and I recommended an employee to use the EAP provided by my work to deal with the problem, I would have trust in the EAP to keep any information about the employee confidential if they attended it:

$\begin{array}{lllllll}1 & 2 & 3 & 4 & 5 & 6\end{array}$

strongly disagree

strongly agree

13. I perceive the EAP provided by my work as being effective in treating drug abuse problems:

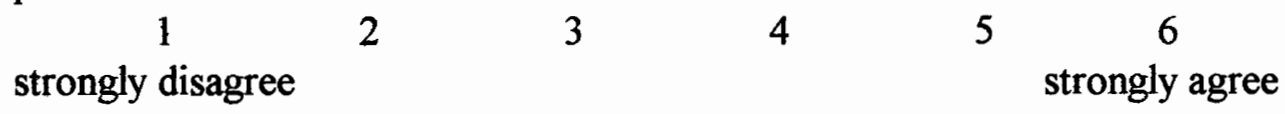

14. If I felt an employee had a drug abuse problem, I would recommend that employee to use the EAP provided by my work to deal with the problem:

strongly disagree

3

2

4

56

strongly agree

15. I am familiar with the Employee Assistance Program (EAP) provided by my work in treating career problems, such as lack of job satisfaction or troubles with a coworker:

1

strongly disagree
3

2
$\begin{array}{lll}4 & 5 & 6\end{array}$
strongly agree

16. If I felt an employee was experiencing career troubles, and I recommended an employee to use the EAP provided by my work to deal with the problem, I would feel that employee would be embarrassed to attend the EAP:

1

2

strongly disagree
3

4

5

17. If I felt an employee had career problems, and I recommended an employee to use the EAP provided by my work to deal with the problem, I would feel the EAP would 
Referral 46

give the employee the appropriate attention that would be needed to treat the career problem:

1

2

3

4

5

6

strongly disagree

strongly agree

18. If I felt an employee had career troubles, and I recommended an employee to use the EAP provided by our work to deal with the problem, I would feel that the EAP provided by my work would NOT try to take total control of the daily routine of the employee to deal with the problem:
1
2
3

strongly disagree
4
5 strongly agree

19. If I felt an employee had career problems, and I recommended an employee to use the EAP provided by our work to deal with the problem, I would have trust in the EAP to keep any information about the employee confidential if they attended it:

1
strongly disagree

2

$$
3
$$

4 strongly agree

20. I perceive the EAP provided by my work as being effective in treating career problems:

1

2

3

4

5

6

strongly disagree

strongly agree

21. If I felt an employee had career troubles, I would recommend that employee to use the EAP provided by my work to deal with the problem:
12
3
4
56
strongly agree

strongly disagree

22. I am familiar with the Employee Assistance Program (EAP) provided by my work in treating financial problems, such as ways to reduce a debt :

$\begin{array}{cccccc}1 & 2 & 3 & 4 & 5 & 6 \\ \text { strongly disagree } & & & & & \text { strongly agree }\end{array}$


23. If I felt an employee was experiencing financial troubles, and I recommended an employee to use the EAP provided by my work to deal with the problem, I would feel that employee would be embarrassed to attend the EAP:
1
2
3
56
strongly agree

strongly disagree

24. If I felt an employee had financial problems, and I recommended an employee to use the EAP provided by my work to deal with the problem, I would feel the EAP would give the employee the appropriate attention that would be needed to treat the financial problem:

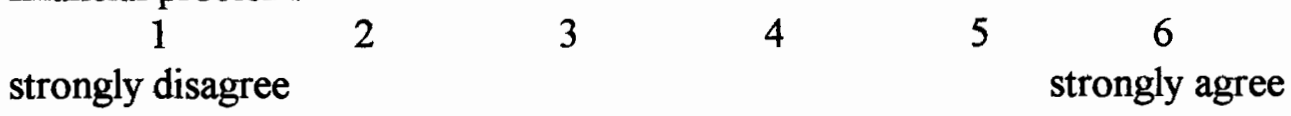

25. If I felt an employee had financial troubles, and I recommended an employee to use the EAP provided by my work to deal with the problem, I would feel that the EAP would NOT try to take total control of the daily routine of the employee to deal with the problem:
1
2
3
4
5
6
strongly agree

strongly disagree

26. If I felt an employee had financial problems, and I recommended an employee to use the EAP provided by my work to deal with the problem, I would have trust in the EAP to keep any information about the employee confidential if they attended it:
1
2
3
4
5
6
strongly agree

strongly disagree

27. I perceive the EAP provided by my work as being effective in treating financial problems:

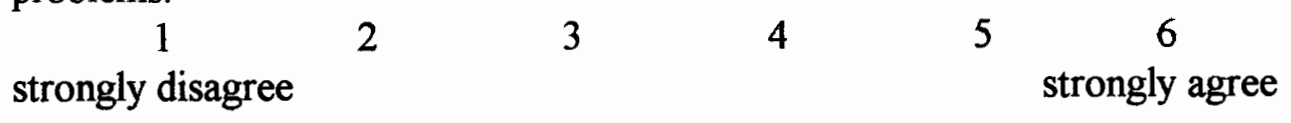

28. If I felt an employee had financial troubles, I would recommend that employee to use the EAP provided by my work to deal with the problem:

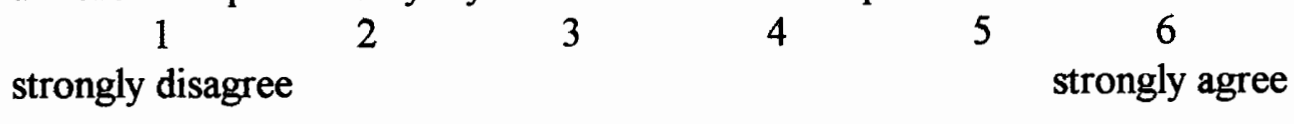


Referral 48

29. I am familiar with the Employee Assistance Program (EAP) provided by my work in treating family problems, such as marital troubles :

$\begin{array}{llllll}1 & 2 & 3 & 4 & 5 & 6\end{array}$

strongly disagree strongly agree

30. If I felt an employee was experiencing family troubles, and I recommended an employee to use the EAP provided by our work to deal with the problem, I would feel that employee would be embarrassed to attend the EAP:

1

strongly disagree
3

4
56

strongly agree

31. If I felt an employee had family problems, and I recommended an employee to use the EAP provided by my work to deal with the problem, I would feel the EAP would give the employee the appropriate attention that would be needed to treat the problem:

1

strongly disagree
2

3
4
5 strongly agree

32. If I felt an employee had family troubles, and I recommended an employee to use the EAP provided by my work to deal with the problem, I would feel that the EAP would NOT try to take total control of the daily routine of the employee to deal with the problem:

$\begin{array}{lllllc}1 & 2 & 3 & 4 & 5 & 6 \\ \text { disagree } & & & & & \text { strongly agree }\end{array}$

33.. If I felt an employee had family problems, and I recommended an employee to use the EAP provided by my work to deal with the problem, I would have trust in the EAP to keep any information about the employee confidential if they attended it:

1

strongly disagree
2

3
4

5

strongly agree

34. I perceive the EAP provided by my work as being effective in treating family problems:

1

2

3

4

5

6

strongly disagree

strongly agree 


\begin{tabular}{|c|c|}
\hline $\begin{array}{l}1=\text { Strongly Disagree } \\
2=\text { Disagree }\end{array}$ & $\begin{array}{l}4=\text { Slightly Agree } \\
5=\text { Agree }\end{array}$ \\
\hline 3 - Slightly Disagree & 6 - Strongly Agree \\
\hline
\end{tabular}

35. If I felt an employee had family troubles, I would recommend that employee to use the EAP provided by my work to deal with the problem:
12
3
4
5
6
strongly agree

strongly disagree

36. I am familiar with the Employee Assistance Program (EAP) provided by my work in treating psychological problems, such as depression:

$\begin{array}{llllll}1 & 2 & 3 & 4 & 5 & 6\end{array}$

strongly disagree strongly agree

37. If I felt an employee was experiencing psychological troubles, and I recommended an employee to use the EAP provided by our work to deal with the problem, I would feel that employee would be embarrassed to attend the EAP:

strongly disagree

23

4

5

6

strongly agree

38. If I felt an employee had psychological problems, and I recommended an employee to use the EAP provided by my work to deal with the problem, I would feel the EAP would give the employee the appropriate attention that would be needed to treat the problem:

12

34

5

6

strongly disagree

strongly agree

39. If I felt an employee had psychological troubles, and I recommended an employee to use the EAP provided by my work to deal with the problem, I would feel that the EAP would NOT try to take total control of the daily routine of the employee to deal with the problem :
12
23
34
5
5

strongly disagree 
40.. If I felt an employee had psychological problems, and I recommended an employee to use the EAP provided by my work to deal with the problem, I would have trust in the EAP to keep any information about the employee confidential if they attended it:

$\begin{array}{cccccc}1 & 2 & 3 & 4 & 5 & 6 \\ \text { strongly disagree } & & & & & \text { strongly agree }\end{array}$

41. I perceive the EAP provided by my work as being effective in treating psychological problems:

$\begin{array}{cccccc}1 & 2 & 3 & 4 & 5 & 6 \\ \text { strongly disagree } & & & & & \text { strongly agree }\end{array}$

42. If I felt an employee had psychological troubles, I would recommend that employee to use the EAP provided by my work to deal with the problem:

1

strongly disagree
3

2
4
5 strongly agree

Please answer the following questions in the space provided to the right.

43. Gender: 1. Female 2. Male

44. Are you married? 1. Yes 2. No

45. Do you have children? 1. Yes 2. No

46. What is your age?

47. How many years have you worked at your current job? 
48. Please state your level of education:

1. Less than high school

2. High school graduate

3. Some college

4. College degree

49. Have you ever used your company's EAP before? 1. Yes 2. No

Thank you for participating in this study. Once again, your answer will be anonymous and will not be reported to any member of your company. If you have any comments please feel free to write them in the space provided below.

Comments: 


\section{Referral 52}

Figure 1

Model For Examining EAP Utilization from Hall et al.

\section{Sociodemographic}

Age

Race

Sex

Job category

Income

Education

\section{Sociocultural}

One's social support network

\section{Organizational}

Employee perception of supervisor's attitudes towards EAP

Convenience of EAP

Confidentiality of EAP

Use of EAP to Keep Job

Propensity to use EAP

Social Psychological

Problem recognition

Problem severity

\section{Community}

Previous Use

Knowledge of other services

Cost of other services

Convenience of other services 
Table 1

Significant predictors of EAP usage from Hall et al. (1991)

Type of problem

Significant variable

$\underline{\beta} \quad \underline{p}$

\begin{tabular}{llll}
\hline Alcohol & Confidentiality & 1.071 & $<.01$ \\
Alcohol & Knowledge & 2.706 & $<.01$ \\
Career & Convenience & 0.886 & $<.01$ \\
Drug & Confidentiality & 0.897 & $<.01$ \\
Drug & Supervisor's attitude & 1.165 & $<.01$ \\
Drug & Knowledge & 2.764 & $<.01$ \\
Psychological & Confidentiality & 0.632 & $<.01$ \\
Family & Knowledge & 2.157 & $<.01$ \\
Financial & Use of EAP to keep job & -0.586 & $<.01$ \\
Supervisor referral & Use of EAP to keep job & -0.197 & $<.07$ \\
Supervisor referral & Supervisor's attitude & 0.303 & $<.01$ \\
& & & \\
\hline
\end{tabular}


Table 2

Employee attitudes towards the EAP

Attitude Definition Sample Question

Familiarity How familiar employee is with "I am familiar with the EAP provided by what is done with the EAP. my work in treating alcohol abuse"

Embarrassment How embarrassed employee "I would feel embarrassed if I attended would be if others knew he/she the EAP provided by my for a drug abuse went to the EAP. problem"

Attention How much personal attention "I would feel the EAP would give me the one would have from EAP. appropriate attention that I would need to treat my career problems"

Effectiveness How effective is EAP for "I perceive the EAP as being effective in treating employees' problems. assisting me with financial problems"

Trust How much employee feels EAP "I would have trust in the EAP to keep can be trusted to keep information confidential.

Control How much would the EAP try to influence the way one acts or the EAP would NOT thinks.

Supervisor referral Would employee attend an EAP if they were referred to go by their immediate supervisor. any information confidential about me if I attended it for family problems" "I would feel that the EAP would NOT
try to take control of my daily routine if I attended it for psychological problems" "If my supervisor recommended that I attend the EAP because he/she felt I was experiencing family troubles, I would
attend" 


\section{Referral 55}

Table 3

Mean willingness to refer to an EAP for employees and supervisors by referral reason

\begin{tabular}{lllllll}
\hline & \multicolumn{3}{c}{ Employees Supervisors } & \multicolumn{3}{c}{ Overall } \\
\cline { 2 - 6 } Referral reason & $\underline{\mathrm{M}}$ & $\underline{\mathrm{SD}}$ & $\underline{\mathrm{M}}$ & $\underline{\mathrm{SD}}$ & $\underline{\mathrm{M}}$ & $\underline{\mathrm{SD}}$ \\
\hline Alcohol abuse & 3.81 & 1.60 & 4.86 & 1.25 & 4.23 & 1.29 \\
Drug abuse & 3.75 & 1.56 & 4.64 & 1.14 & 4.17 & 1.43 \\
Psychological & 3.46 & 1.66 & 4.19 & 1.15 & 3.80 & 1.48 \\
Financial & 3.47 & 1.16 & 4.33 & 1.27 & 3.88 & 1.28 \\
Career & 3.59 & 1.42 & 4.45 & 1.09 & 4.00 & 1.34 \\
Family & 3.89 & 1.17 & 4.67 & 1.08 & 4.26 & 1.19 \\
\hline
\end{tabular}

Note: Willingness to refer ranges from 1 to 6 
Table 4

Mean willingness to refer to an EAP for males and females by referral reason

\begin{tabular}{lllll}
\hline & \multicolumn{2}{c}{ Males } & \multicolumn{2}{c}{ Females } \\
\cline { 2 - 5 } Referral reason & $\underline{\mathrm{M}}$ & $\underline{\mathrm{SD}}$ & $\underline{\mathrm{M}}$ & $\underline{\mathrm{SD}}$ \\
\hline & & & & \\
\hline Alcohol abuse & 4.24 & 1.52 & 4.21 & 1.49 \\
Drug abuse & 4.19 & 1.43 & 4.15 & 1.46 \\
Psychological & 3.64 & 1.55 & 3.97 & 1.40 \\
Financial & 3.61 & 1.25 & 4.30 & 1.21 \\
Career & 3.73 & 1.41 & 4.18 & 1.26 \\
Family & 4.11 & 1.17 & 4.42 & 1.20 \\
\hline
\end{tabular}

Note: Willingness to refer ranges from 1 to 6 
Table 5

Mean willingness to self refer to an EAP for no prior EAP usage and prior EAP usage by referral reason

\begin{tabular}{lllll}
\hline & \multicolumn{2}{c}{ Not used EAP } & \multicolumn{2}{c}{ Used EAP } \\
\cline { 2 - 5 } Referral reason & $\underline{\mathrm{M}}$ & $\underline{\mathrm{SD}}$ & $\underline{\mathrm{M}}$ & $\underline{\mathrm{SD}}$ \\
\hline Alcohol abuse & 3.58 & 1.50 & 5.06 & 1.00 \\
Drug abuse & 3.54 & 1.37 & 5.00 & 1.05 \\
Psychological & 3.26 & 1.52 & 4.50 & 1.11 \\
Financial & 3.63 & 1.21 & 4.68 & 0.94 \\
Career & 3.46 & 0.94 & 4.24 & 1.21 \\
Family & 3.72 & 0.85 & 4.94 & 0.85 \\
& & & & \\
\hline
\end{tabular}

Note: Willingness to refer ranges from 1 to 6 
Table 6

Multiple regression analyses of attitudes towards EAP on willingness to self refer by type of problem

\begin{tabular}{|c|c|c|c|c|c|c|c|c|c|c|c|c|c|c|}
\hline \multirow[t]{2}{*}{ Problem } & \multirow[b]{2}{*}{$\underline{\mathrm{R}}^{2}$} & \multicolumn{2}{|c|}{ Attention } & \multicolumn{2}{|c|}{ Control } & Embarrassment & \multicolumn{2}{|c|}{ Familiarity } & \multicolumn{2}{|c|}{ Trust } & \multicolumn{2}{|c|}{ Effectiveness } & \multicolumn{2}{|c|}{ Referral } \\
\hline & & $\underline{\beta}$ & $\mathrm{p}$ & $\underline{\beta}$ & $\mathrm{p}$ & $\underline{\beta}$ & $\underline{\beta}$ & $\mathrm{p}$ & $\underline{\beta}$ & $\underline{p}$ & $\underline{\beta}$ & $\mathrm{p}$ & $\underline{\beta}$ & $\mathrm{p}$ \\
\hline Alcohol & .78 & .49 & .01 & .43 & .01 & .29 .01 & .25 & .08 & .08 & .41 & .19 & .25 & .14 & .32 \\
\hline Drug & .88 & -.06 & .60 & .59 & .01 & $.08 \quad .40$ & .05 & .61 & .35 & .01 & -.01 & .90 & .31 & .01 \\
\hline Psych. & .86 & -.10 & .41 & .54 & .01 & -.10 .34 & -.01 & .91 & .49 & .01 & .19 & .11 & .43 & .01 \\
\hline Career & .80 & -.08 & .69 & -.05 & .67 & .00 .98 & .13 & .24 & .11 & .29 & .52 & .01 & .72 & .01 \\
\hline Financial & .79 & .12 & .36 & .32 & .01 & -.16 .11 & -.02 & .83 & .05 & .69 & -.11 & .38 & .76 & .01 \\
\hline Family & .85 & .09 & .54 & .40 . & .01 & -.15 .19 & .09 & .61 & .57 & .01 & .11 & .43 & .43 & .01 \\
\hline
\end{tabular}

Note: All $\underline{R}^{2}$ 's were significant at the .01 level 
Referral 59

Table 7

Univariate ANOVA results of self versus supervisory referrals to an EAP by referral reason

\begin{tabular}{llll} 
Referral reason & $\underline{\mathrm{df}}$ & $\underline{\mathrm{F}}$ & $\mathrm{p}$ \\
\hline Alcohol abuse & 1,69 & 6.40 & 0.01 \\
Drug abuse & 1,67 & 7.17 & 0.01 \\
Psychological & 1,67 & 4.35 & 0.04 \\
Financial & 1,67 & 8.70 & 0.01 \\
Career & 1,68 & 7.90 & 0.01 \\
Family & 1,68 & 8.19 & 0.01 \\
& & & \\
\hline
\end{tabular}


Table 8

Multiple regression analyses of attitudes towards EAP on supervisors' willingness to refer employees to an EAP by type of problem

\begin{tabular}{|c|c|c|c|c|c|c|c|c|c|c|c|c|c|}
\hline \multirow[t]{2}{*}{ Problem } & \multirow[b]{2}{*}{$\underline{R^{2}}$} & \multicolumn{2}{|c|}{ Attention } & \multicolumn{2}{|c|}{ Control } & \multicolumn{2}{|c|}{ Embarrassment } & \multicolumn{2}{|c|}{ Familiarity } & \multicolumn{2}{|c|}{ Trust } & \multicolumn{2}{|c|}{ Effectiveness } \\
\hline & & $\underline{\beta}$ & $\mathrm{p}$ & $\underline{\beta}$ & $\mathrm{p}$ & $\underline{\beta}$ & $\mathrm{p}$ & $\underline{\beta}$ & $\mathrm{p}$ & $\underline{\beta}$ & $\underline{p}$ & $\underline{\beta}$ & $\mathrm{p}$ \\
\hline Alcohol & .76 & .09 & .54 & .56 & .01 & .18 & .15 & .08 & .43 & .45 & .01 & .14 & .31 \\
\hline Drug & .56 & .16 & .21 & .51 & .01 & .14 & .26 & .19 & .11 & .09 & .37 & .35 & .01 \\
\hline Psych. & .49 & .20 & .54 & .06 & .80 & -.08 & 3.61 & .10 & .51 & .06 & .79 & .43 & .01 \\
\hline Career & .60 & .24 & .15 & .25 & .21 & -.01 & .92 & -.02 & .84 & .16 & .33 & .47 & .04 \\
\hline Financial & .51 & .12 & .38 & .64 & .01 & -.05 & 5.66 & .05 & .54 & .02 & .88 & .32 & .01 \\
\hline Family & .72 & .32 & .04 & .03 & .82 & .04 & .68 & .03 & .76 & .05 & .78 & .53 & .01 \\
\hline
\end{tabular}

Note: All $\underline{\mathrm{R}}^{2}$ 's were significant at the .01 level 
Referral 61

Table 9

Univariate ANOVA results of previous EAP usage versus non usage by referral reason

\begin{tabular}{llll} 
Referral reason & $\underline{\mathrm{df}}$ & $\underline{\mathrm{F}}$ & $\underline{\mathrm{p}}$ \\
\hline Alcohol abuse & 1,69 & 22.72 & 0.01 \\
Drug abuse & 1,67 & 23.40 & 0.01 \\
Psychological & 1,67 & 14.29 & 0.01 \\
Financial & 1,67 & 4.09 & 0.05 \\
Career & 1,68 & 17.63 & 0.01 \\
Family & 1,68 & 24.25 & 0.01
\end{tabular}


Table 10

Summary of significant predictors for willingness to self refer and supervisory referral to an EAP by type of problem

\section{Significant Predictors}

Problem Self Referrals $\quad$ Supervisory Referrals

$\begin{array}{lll}\text { Alcohol } & \text { attention, control, embarrassment } & \text { trust, control } \\ \text { Drug } & \text { control, trust, referral } & \text { effectiveness, control } \\ \text { Psych. } & \text { control, trust, referral } & \text { effectiveness } \\ \text { Career } & \text { referral, effectiveness } & \text { effectiveness } \\ \text { Financial } & \text { control, referral } & \text { effectiveness, control } \\ \text { Family } & \text { control, trust, referral } & \text { effectiveness, attention }\end{array}$

